\title{
Interprovincial Migration and the Stringency of Energy Policy in China
}

\author{
Xiaohu Luo ${ }^{* \ddagger}$, Justin Caron ${ }^{\ddagger}$, , Valerie J. Karplus ${ }^{\ddagger}$, Da Zhang ${ }^{\ddagger}$, Xiliang Zhang ${ }^{*, \dagger}$
}

\begin{abstract}
Interprovincial migration flows involve substantial relocation of people and productive activity, with implications for regional energy use and greenhouse gas emissions. In China, these flows are not explicitly considered when setting energy and environmental targets for provinces, and their potential impact on the effectiveness of policy alternatives is ignored. We analyze how migration affects outcomes under energy intensity targets and energy caps. While both policies are part of the nation's Twelfth Five Year Plan (2011-2015) and imposed at the provincial level, only the intensity targets are binding at present. We estimate a migration model, integrate it into a general equilibrium model that resolves each province in China, and simulate the effect of migration on energy use and economic activity. We find that although both types of policies are affected by uncertain migration flows, energy intensity targets (energy use indexed to economic output) are more robust than absolute caps. They are also more cost-effective, placing less burden on the relatively clean in-migration provinces. Our findings also underscore the value of moving from provincial targets to an integrated national emissions trading system, given that the choice of abatement strategies will adjust endogenously to labor relocation.
\end{abstract}

Keywords: migration, labor mobility, China, energy demand, climate policy, energy policy

\section{Contents}

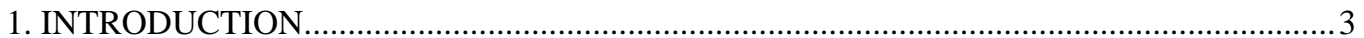

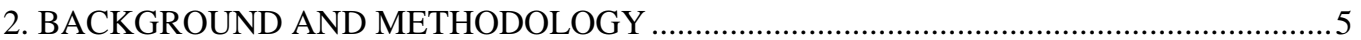

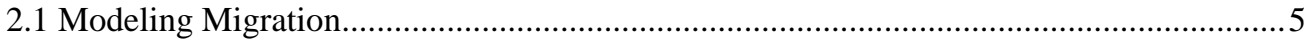

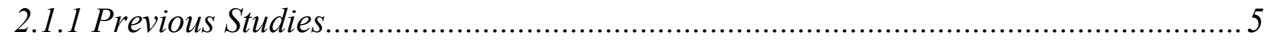

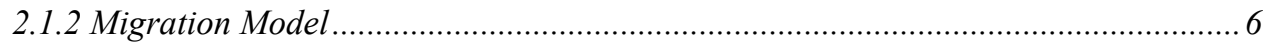

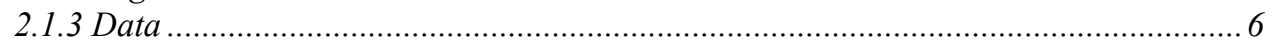

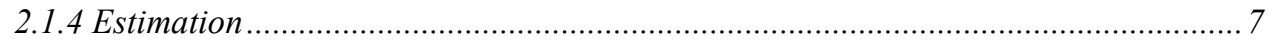

2.2 Modeling China’s Regional Economy and Energy Use ..................................................... 8

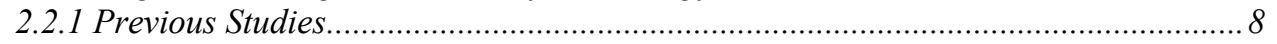

2.2.2 China Regional Energy Model (C-REM) .......................................................... 9

2.3 Model Coupling ...............................................................................................................1

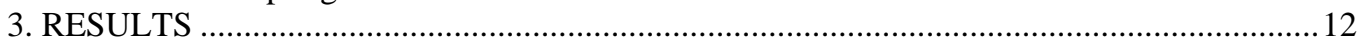

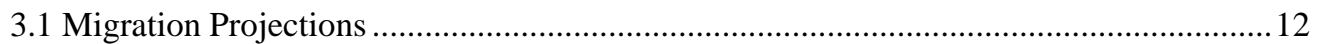

3.2 Baseline Projection for GDP and Energy Use …….........................................................13

3.3 Policy Simulation .............................................................................................................. 18

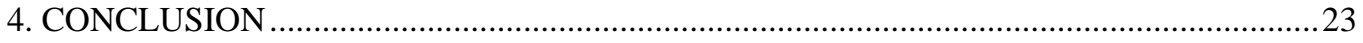

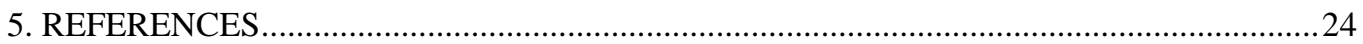

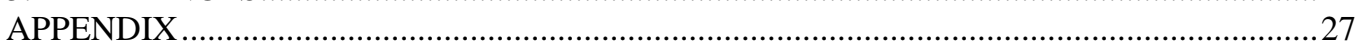

* Institute of Energy, Environment, and Economy, Tsinghua University, Beijing, China.

${ }^{\ddagger}$ Joint Program on the Science and Policy of Global Change, Massachusetts Institute of Technology, MA, USA. \# Department of Applied Economics, HEC Montréal, Montréal, QC, Canada

${ }^{\dagger}$ Corresponding author: Insitute of Energy, Environment \& Economy; Energy Science Building C30; Tsinghua University; Beijing 100084; China; Phone: +86-10-62796166; Fax: + +86-10-62772759; E-

mail: zhang_xl@tsinghua.edu.cn 


\section{INTRODUCTION}

Several decades of rapid economic growth in China have brought great benefits as well as serious environmental challenges. To address the country's rapidly rising energy use and $\mathrm{CO}_{2}$ emissions, China's leaders have implemented mandatory energy and carbon intensity targets and non-binding energy caps as part of the Twelfth Five-Year Plan (FYP) (China State Council, 2011). The present policy approaches builds on recent efforts to regulate energy intensity and increase awareness that the environmental footprint of China's energy sector is not sustainable. While energy saving and emissions reductions have been mentioned in China's annual reports since the Sixth FYP (1981-1986), it was not until the Eleventh FYP (2006-2010) that a binding target for energy intensity reduction was introduced. A binding carbon intensity target was added to the Twelfth FYP, reflecting China's commitment at the international climate negotiations in Copenhagen to reduce its carbon intensity by 40-45\% from 2005 levels by 2020 (Xinhua Net, 2009). Energy caps have only recently been more widely discussed as a mechanism for limiting energy use. All targets - for energy and carbon intensity as well as total energy use-have historically been assigned at the level of individual provinces, although policymakers have recently announced intentions to link provincial energy and carbon markets using an emissions trading system.

This paper examines the interaction of these provincially-set policy designs with a mainstay of China's economic development process: interprovincial migration. While past scholarship has proposed a wide range of indices_-provincial gross domestic product (GDP), per capita income, population, energy use, energy production and industry output shares - to disaggregate targets at the provincial level, to our knowledge none have accounted for migration. Among research groups that have provided input to the National Development and Reform Commission (NDRC) in the target-setting process, none has included migration in published analysis (Wei, 2012; Yi, 2011). Nevertheless, sheer volumes suggest that migration is likely to be very important - total interprovincial migration flows reached 100 million between 2001 and 2010 (NBS, 2012). Longstanding restrictions on migration following from China's household registration (or hukou system) have led to large gaps in wages and living standards (including access to health care and education) among provinces (Whalley and Zhang, 2007). In recent years, hukou restrictions have gradually been relaxed, allowing for an increasing share of the country's population to relocate in search of employment. At the same time, rapidly expanding transportation infrastructure (e.g. high speed rail) has made inter-city travel more convenient. As a result of these favorable conditions, the number of migrants who have relocated, either temporarily or permanently, to richer areas (mostly eastern provinces such as Beijing, Shanghai, Guangdong, Jiangsu, and Zhejiang) has been growing very fast in the last 5 to 10 years (Shen, 2013). For instance, according to the National Bureau of Statistics of China (NBS, 2012), Beijing's population grew from 10.86 million in 1990 to 19.62 million in 2010, at an annual growth rate of about 3.2\%clearly above China's natural population growth rate of $0.8 \%$. Also, the pace of migration has accelerated in the last few years; in 2010, Beijing saw one million new migrants-more than 5\% of the city's population. 
Depletion in the potential migrant pool as well as declining wage differentials across provinces will necessarily slow migration in the future. Despite this, a redoubled emphasis by China's leaders (Li, 2013) on urbanization as a key element of the country's growth strategy going forward means that the rates of migration both within and between provinces are unlikely to abate anytime soon. Given the obvious importance of migration within China, a surprisingly small number of studies mention its effect on energy use and energy policy. Some, such as Auffhammer and Carson (2008), provide evidence that interprovincial migration affects energy use and carbon emissions at the provincial level. To our knowledge, no study has explicitly investigated the link between migration and energy or climate policy. We aim to fill this gap in the literature by analyzing the relationship between interprovincial migration and the projected outcomes of alternative energy policy designs.

Migration affects energy use through several channels. Population shifts affect not only the scale of economic activity but also the structure of the economy. Changes in the relative availability and cost of labor and other primary factors of production will exert disproportionate influence across production sectors. More precisely, an increase in the labor supply will benefit industries in proportion to their labor intensity. Migration may also exacerbate the unbalanced regional mapping between economic development and energy production. In China, coastal provinces are more economically prosperous but short of resources, while central and western regions are rich in resources but lag in economic development. Migration from west to east could strain already scarce energy and resource supplies in the east as total demand increases; this trend will exacerbate energy transport or electricity transmission bottlenecks involved in delivering energy to population centers. Energy policy that fails to consider these dynamics could impose high and concentrated costs on some provincial economies.

To quantify the impact of migration on the energy system and its interaction with energy policy, we build a model that endogenously determines migration flows and embed it in a province-level general equilibrium model. This approach allows us to dynamically track the interactions between migration, economic output and energy use. The migration model is used to project migration flows to 2020, and allows us to simulate their effect on the patterns of energy production and energy use as well as changes in the relative energy intensities of provinces.

Our work contributes to ongoing research on energy and climate policy design in China, as well as literature on the robustness of policy design in the face of uncertain factors (O'Neill et al. 2012). Our analysis yields several findings. First, we find that migration increases total national GDP as more people move to more productive provinces, and reduces total energy intensity as more people move to less energy-intensive provinces. ${ }^{1}$ Second, we find that migration further widens the gap in energy intensity between the (more energy-intensive) out-migration provinces and (less energy-intensive) in-migration provinces. Out-migration provinces see a reduced

\footnotetext{
${ }^{1}$ This result depends crucially on the assumed energy use profile of migrants, both in their province of origin prior to migrating and their destination province after relocation. In this study, we assume migrants adopt the consumption behavior (productivity and consumption patterns) of the average resident in the destination province.
} 
comparative advantage in services and greater comparative advantage in the production of resource-intensive goods, while the opposite occurs in in-migration provinces. As a result, energy intensity targets place a greater burden on out-migration provinces. In contrast, energy caps do not adjust to changes in economic productivity, and thus place a greater burden on the in-migration provinces (which, due to their rapid growth, use more energy in absolute terms relative to a no-migration scenario). Energy intensity targets are thus more robust ${ }^{2}$ than energy caps to migration flows. Since migration affects energy intensity as well, the energy intensity targets are not completely robust to migration, but in relative terms they outperform the less flexible energy caps in the face of unanticipated migration flows. Energy caps are less robust because they do not reflect changes in economic activity caused by shifts in underlying factor and structural conditions.

Third, highly energy intensive out-migration provinces have cheaper reduction possibilities than the cleaner in-migration provinces; therefore, energy intensity targets — which tend to place a greater burden on out-migration provinces-may reduce energy use at a lesser cost. Thus, intensity targets are also preferable in terms of economic efficiency, as they result in greater energy use reduction with lower associated welfare loss.

\section{BACKGROUND AND METHODOLOGY}

To simulate the interaction between migration and energy policy in China, we develop a novel approach for representing population flows within a recursive-dynamic general equilibrium model of China's energy and economic system that separately resolves the nation's 30 provinces and projects migration flows as a function of economic opportunity. Below we discuss how the relationships governing migration are estimated and embedded within the simulation model, building on previously established methods that (to our knowledge) have not been jointly applied.

\subsection{Modeling Migration}

\subsubsection{Previous Studies}

Economists have long studied migration of labor and its relationship with patterns of economic activity. Starting with Ravenstein (1885), scholars have related migration to income, language, distance, and other factors such as age, sex and education. These factors have been incorporated into a wide range of models used to project future migration patterns (Kau and Sirmans, 1979; Ma and Wang, 2012; Simini et al., 2012). Gravity models have been widely used to represent migration flows as being dependent on characteristics of both the origin and destination regions as well as the distance between them (Hua and Porell, 1979). Equation 1 is a generalized representation of the gravity model as proposed by Zipf (1946):

$$
M_{i, o}=\frac{P_{i}^{\alpha} P_{o}^{\beta}}{D_{i, o}}
$$

\footnotetext{
${ }^{2}$ We define robustness as the change in the relative magnitude of economic losses due to policy in each province, relative to a no-migration scenario.
} 
In this equation, $M_{i, o}$ represents the number of migrants moving from province $o$ to province $i, P_{i}$ is the population of the destination (in-migration) province, $P_{o}$ is the population of the origin (out-migration) province, $D_{i, o}$ is the distance between the two regions, and $\alpha$ and $\beta$ are the estimated coefficients associated with each factor. Gravity models have been widely applied and expanded to include factors such as income, health care, education, and transportation infrastructure (Dustmann 2003; Lipton 1980; Michael 2003). In general, these models fit migration patterns quite well. Almost all studies agree that per capita income or wages are closely linked to migration decisions. Similarly, research on China has found that income is most important driver of migration (Hu 2002; Zhao and Meng 1999; Zhu 2002).

\subsubsection{Migration Model}

We model migration flows between province pairs as a function of population, average income and past migration. Following the generalized form of the gravity model shown in Equation 1, we estimate a log-log relationship using a panel of historical data similar to Westerlund and Wilhelmsson (2011).

The generalized model is shown in Equation 2:

$$
\ln M_{i, o, t}=a_{1} \operatorname{lnPop}_{i, t-1}+a_{2} \operatorname{lnPop}_{o, t-1}+a_{3} \operatorname{lnGDPpcap}_{i, t-1}+a_{4} \operatorname{lnGDPpcap}_{o, t-1}+a_{5} \ln _{i, o, t-1}
$$

Migration $(M)$ in time period $t$ from province $o$ to province $i$ is a function of the population (Pop) of each province, per-capita GDP (GDPpcap) in each province, and the level of migration between the two provinces in the previous period. Allowing migration flows to depend on past migration captures structural factors affecting average levels of migration, such as distance, cultural ties, and transport linkages (these are not directly observed, but they do not change over time). Including past migration as an independent variable also prevents province pairs with very low migration numbers from disproportionally affecting the coefficient estimates.

\subsubsection{Data}

Data include migration flows between each pair of 30 provinces (without Tibet, Hong Kong, Macao and Taiwan), forming a total of 870 data points for three time periods (1995-2000, 20002005 and 2005-2010). Data are supplied by China's National Bureau of Statistics, which conducted a national census of the entire population in 2000 and 2010. We supplement these data with population surveys covering 10\% of the total population in the intervening years 1995 and 2005. Of the census participants, $10 \%$ were asked to fill out a long-form questionnaire including data on the household's migration patterns. The form asked individuals to state their residence status at the time of submission and five years prior (as migrants are defined as individuals who changed their province of permanent residence during each five-year period). Survey totals are rescaled to obtain an estimate of the total migration flows between province pairs.

We find that migration is concentrated in a small number of province pairs (90\% of migration occurs in about 50 of 870 total pairs). We also find that migration is concentrated among the working-age population. The vast majority of migrants from 2000 to 2005 were ages 15-40; children and the elderly are not nearly as mobile. At present, the volume of migration in China is 
large and increasing. From 2005 to 2010, the total volume of migration between provinces reached 61 million people-approximately the population of Italy. As shown in Figure 1, 20052010 net migration inflows were concentrated in Beijing and other provinces along the southeast coast including Shanghai, Jiangsu, Zhejiang and Guangdong; net outflows are concentrated in the center and northeast. Data describing provincial population and per capita GDP also come from China's National Bureau of Statistics (NBS, 2012). We use provincial per-capita gross domestic product (GDP) instead of per-capita income in our model. ${ }^{3}$

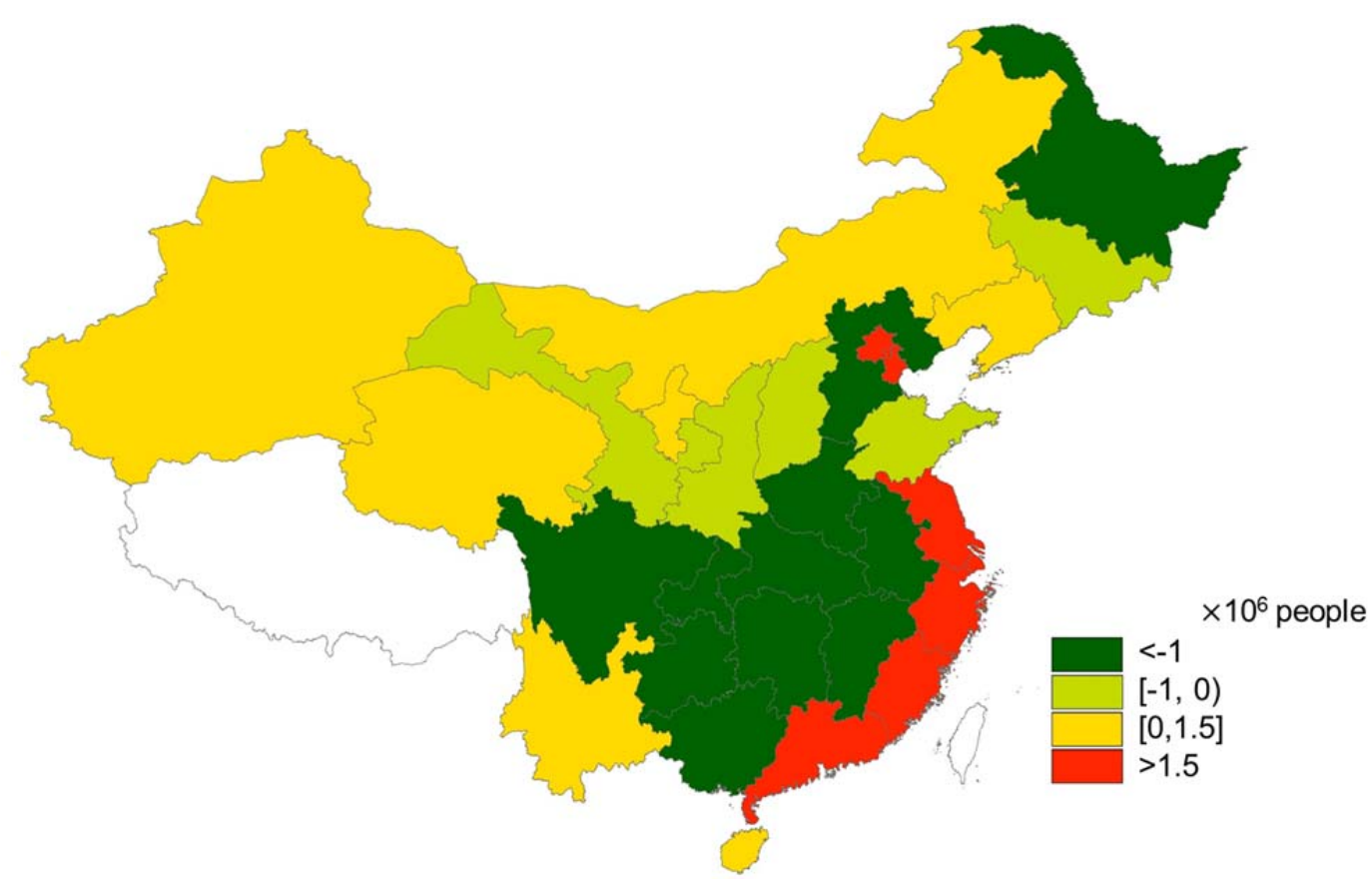

Figure 1. Net migration between 2005 and 2010 (NBS, 2012).

\subsubsection{Estimation}

Given that migration flows are positive and discrete, the migration model described in Equation 2 is estimated using Poisson Maximum-Likelihood, as is standard in the gravity literature (Flowerdew and Aitkin, 1982). We first impose restrictions on the model to identify the contributions of lagged population, per capita GDP, population and per capita GDP, and past migration (see first 4 columns of Table 1). We find past migration between two provinces to explain 95\% of the variability in migration patterns, making it the strongest determinant of

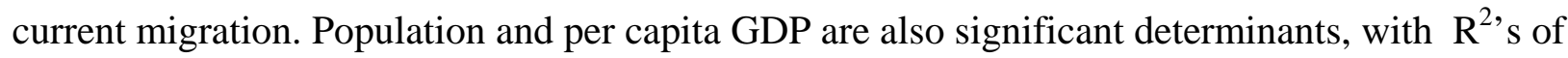
0.23 and 0.26 . In the Full Specification (see last column of Table 1), we find that on average a $1 \%$ increase in the population of the destination province in the previous period $(\mathrm{t}-1)$ results in a $0.09 \%$ increase in in-migration, while a $1 \%$ increase in the population of the origin province

\footnotetext{
${ }^{3}$ The correlation between GDP per capita and average income is 0.87 (calculated from NBS, 2012). We chose to use per-capita GDP because its source is the national accounts, which are deemed more reliable than income data which are sourced from household surveys.
} 
increases the volume of out-migration by $0.14 \%$. The effect of GDP per capita is larger in magnitude and statistically significant-a 1\% increase in GDP per capita in the destination province in the previous period results in a $0.346 \%$ rise in the expected count of migrants, while the GDP per capita of the origin province is estimated to have a negative but not statistically significant effect. The Aikaike model selection criterium (AIC) is lowest for the full specification, suggesting that the inclusion of all variables is warranted.

Table 1. Migration model - Poisson PML regression results.

\begin{tabular}{|c|c|c|c|c|c|c|c|}
\hline Dep. Var.: $M_{i, o, t}$ & Population & GDP & & Population + GDP & Past Migration & Full S & ecification \\
\hline Population $_{i, t-1}$ & $0.741 \quad(0.000)^{*}$ & & & $1.178(0.119)^{*}$ & & 0.091 & $(0.026)^{\star}$ \\
\hline Population $_{o, t-1}$ & $1.177(0.000)^{*}$ & & & $1.259(0.080)^{*}$ & & 0.142 & $(0.034)^{*}$ \\
\hline GDPpcap $_{i, t-1}$ & & 1.430 & $(0.070)^{*}$ & $2.118(0.121)^{*}$ & & 0.346 & $(0.039)^{*}$ \\
\hline GDPpcap $_{o, t-1}$ & & -0.711 & $(0.117)^{*}$ & $-0.838 \quad(0.122)^{*}$ & & -0.047 & $(0.039)$ \\
\hline$M_{i, o, t-1}$ & & & & & $0.936(0.010)^{*}$ & 0.866 & $(0.012)^{*}$ \\
\hline Constant & $-22.705(0.005)^{*}$ & 3.772 & $(1.231)^{*}$ & $-44.588(3.414)^{*}$ & $1.096(0.113)^{*}$ & -5.176 & $(1.012)^{*}$ \\
\hline Observations & 1740 & 1740 & & 1740 & 1740 & 1740 & \\
\hline $\mathbf{R}^{2}$ & 0.227 & 0.266 & & 0.589 & 0.950 & 0.958 & \\
\hline AIC & 24.8 & 23.7 & & 13.2 & 1.58 & 1.37 & \\
\hline
\end{tabular}

Standard errors in parenthesis; * denotes significance at the $1 \%$ level; AIC is the Akaike information criterion.

These estimates imply that while migration projections based on our model will primarily reflect the effect of past migration, they will also be influenced by provincial population and per capita GDP. Including population and per-capita GDP in addition to historical migration is important to capture the potentially attenuating effect of regional demographic and economic changes that could cause migration to deviate from past patterns.

\subsection{Modeling China’s Regional Economy and Energy Use}

\subsubsection{Previous Studies}

Methods for projecting energy use and economic activity differ in the level of technology detail and macroeconomic feedbacks captured (Böhringer and Rutherford, 2009). To study migration and its interactions with energy policy, a model needs to resolve both the key drivers of migration and resulting population flows as well as how migration changes local factor endowments and prices. For this purpose, we use a computable general equilibrium (CGE) model with regional economic and energy system detail. CGE models have been widely used to study the economy-wide impact of energy policies by simulating effects on relative prices (Laitner and Hanson, 2006; Rausch et al., 2011). CGE models have also been applied to study energy policies, including energy taxes (Dai et al. 2011), emissions caps, emissions taxes (Cao, 2007; Liang and Wei, 2012; Wang et al., 2011), emissions intensity targets (Wang et al., 2009), and energy subsidies and related reforms (Lin and Jiang, 2011).

Studying the impact of migration within China and its interaction with energy policy requires a model with sub-national detail. While models used in the studies cited above represent China as a single region, a growing number of studies include provincial detail (Cui et al., 2014; Tang and Wu 2013; Zhang et al. 2013). 
Our work contributes to previous literature that has studied migration (or changes in labor endowments) within a CGE framework (Flaig et al. 2013; Rutherford 2001). In these models, wage differentials drive migration among sectors and regions. This approach fails to capture the historical structure of migration patterns (and the drivers implicit in them). Factors such as income, population, education and access to transportation change with time, while others are permanent (e.g. distances between regions, cultural differences, and language). We therefore adopt a novel approach that embeds a migration model calibrated using historical data within a CGE framework and solve recursively for economic activity, energy use, and migration flows.

\subsubsection{China Regional Energy Model (C-REM)}

We couple the migration model to the China Regional Energy Model (C-REM), a multi-region, multi-sector, recursive-dynamic global general equilibrium model that represents 30 provinces in mainland China. Sub-national detail in China is parameterized using China's 2007 provincial input-output tables and provincial energy balance tables. The rest of the world is divided into four regions (United States, Europe, other developing countries, and other developed countries), with economic and energy data as well as trade flows among all regions parameterized using the GTAP (Global Trade Analysis Project) data base version $8 .^{4}$ The regional and sectorial aggregation of the C-REM is shown in Table 2.

\footnotetext{
${ }^{4}$ Discrepancies between national and provincial energy statistics in China are well documented (Guan et al., 2012). We
} scale total energy use to match nationally-reported totals, preserving energy type shares based on provincial data. 
Table 2. C-REM regional and sectoral aggregation.

\begin{tabular}{|c|c|c|c|}
\hline \multicolumn{4}{|l|}{ Regional } \\
\hline \multicolumn{4}{|c|}{ Chinese Provinces } \\
\hline Beijing & BJ & Henan & $\mathrm{HA}$ \\
\hline Tianjin & $\mathrm{TJ}$ & Hubei & $\mathrm{HB}$ \\
\hline Hebei & $\mathrm{HE}$ & Hunan & $\mathrm{HN}$ \\
\hline Shanxi & SX & Guangdong & GD \\
\hline Mongolia & NM & Guangxi & GX \\
\hline Liaoning & LN & Hainan & $\mathrm{HI}$ \\
\hline Jilin & $\mathrm{JL}$ & Chongqing & CQ \\
\hline Heilongjiang & $\mathrm{HL}$ & Sichuan & SC \\
\hline Shanghai & $\mathrm{SH}$ & Guizhou & $\mathrm{GZ}$ \\
\hline Jiangsu & JS & Yunnan & YN \\
\hline Zhejiang & ZJ & Shaanxi & $\mathrm{SN}$ \\
\hline Anhui & $\mathrm{AH}$ & Gansu & GS \\
\hline Fujian & FJ & Qinghai & $\mathrm{QH}$ \\
\hline Jiangxi & $\mathrm{JX}$ & Ningxia & NX \\
\hline Shandong & SD & Xinjiang & $\mathrm{XJ}$ \\
\hline \multicolumn{4}{|c|}{ Other Regions } \\
\hline \multicolumn{3}{|c|}{ Other Developed Countries* } & ODC \\
\hline \multicolumn{3}{|l|}{ United States } & USA \\
\hline \multicolumn{3}{|l|}{ Europe $^{5}$} & EUR \\
\hline \multicolumn{3}{|c|}{ Rest of the World } & ROW \\
\hline
\end{tabular}

\begin{tabular}{ll}
\hline Sectoral & \\
\hline Sector & Description \\
\hline COL & Coal mining and processing \\
CRU & Crude petroleum products \\
GAS & Natural gas products \\
OIL & Petroleum refining, cooking \& nuclear fuels \\
EIS & Energy intensive industries \\
\hline MAN & Other manufacturing industries \\
ELE & Electricity and heat \\
WTR & Water \\
CON & Construction \\
TRN & Transportation and Post \\
SER & Services \\
OMN & Metal/non-metal minerals, other mining \\
AGR & Agriculture, forestry, livestock \\
\hline
\end{tabular}

* Other Developed Countries include Australia, Canada, Japan, New Zealand and South Korea.

We extend the static version of C-REM documented in Zhang et al. (2013) to include a dynamic projection to 2010, 2015 and 2020. The projection for 2010 is calibrated to historical observations (NBS, 2012), while projections for 2015 and 2020 reflect a reference regional economic growth assumption (based on the Twelfth Five-Year Plan and near-term expectations of each province, e.g. Guangdong Statistic Bureau (2011)). We calibrate 2010 energy quantities by province to published statistics for the same year by first calibrating the model to observed economic growth, then exogenously tuning energy efficiency to match published energy quantities. Prices evolve endogenously in the C-REM model. Migration and energy policy scenarios affect the relative availability of capital and labor as well as the relative cost of available energy types. The savings rate is calibrated to base year data (as in the MIT EPPA model (Paltsev et al., 2005)) while labor productivity rises at a decreasing rate.

Labor supply $L$ in each region $r$ is updated according to the equation below:

$$
L_{r, t}=N_{r, t} \times S_{r} \times \Omega_{r, t}
$$

Where $N$ is population (determined by the migration model), $S$ is labor force participation, and $\Omega$ is labor productivity per worker. Migration affects $N$ mechanically, but its effect on $S$ and

\footnotetext{
${ }^{5}$ Europe comprises the European Union (EU), the European Free Trade Association (EFTA), EU Custom Union countries and Former Yugoslavian countries.
} 
$\Omega$ is less obvious. ${ }^{6}$ In the absence of conclusive data about the effects of migration on $S$ and $\Omega$, we assume that they are unaffected. Given that we are projecting over a relatively short time horizon (to 2020), $S$ is further assumed to remain constant over the 10-year time horizon of our projection ${ }^{7}$, while the growth rate $g_{r, t}$ of $\Omega_{r, t}$ is calibrated as follows. The initial labor productivity growth rate $g_{r, 0}$ is calibrated to observed economic growth by adjusting the available capital stock for the years 2007 and 2010. We then assume it to decrease over time according to the relationship shown in Equation 4.

$$
g_{r, t}=\left(g_{r, 0}-g_{r, T}\right) \frac{1+\alpha}{1+\alpha^{\beta t}}+g_{r, T}
$$

Where $g_{r, T}$ is the long-term (100 years) growth rate of labor productivity, assumed to be $2 \%$ per year. We adopt values of the shape parameters $\alpha$ and $\beta$ from previous studies, setting them as 0.1 and 0.07 respectively (Paltsev et al., 2005). Productivity will thus adjust from its initial growth rate towards its final long-term value in an S-shaped fashion. Absent migration, each province's population is assumed to grow by $0.48 \%$ per year-the natural population growth rate for China as a whole, forecast by the UN Population Division (UN, 2011).

We also assume that provincial capital stocks in each time period grow according to the provincial value-added growth rate $g_{r, t}$. A portion of capital stock is assumed to malleable in each period and can be repurposed across all sectors, while the remainder of the stock is fixed by its existing uses. This prevents large reallocations of capital between sectors and limits the scope for changes in the economy's structure and in the mix of energy production technologies within each period.

Land, wind, hydropower, and fossil fuel resources are represented as fixed resource as in the MIT EPPA model and shared out by province as in Zhang et al. (2013). Each region in C-REM includes an assumption regarding the speed at which energy efficiency improves over time independently of changes in relative prices. For the United States, this long-run autonomous energy efficiency improvement is assumed to be about $1 \%$ per year (Paltsev et al., 2005), while in Chinese provinces it is estimated to be approximately 2\% (Cao and Ho, 2010). Trade in goods and services is determined according to the Armington assumption of differentiated products by country of origin. Elasticities are calibrated such that domestic goods entering a province are closer substitutes to local goods than to those originating outside of China, as in Caron et al. (2015).

\subsection{Model Coupling}

In order to capture how migration impacts the evolution of China's economy and energy systems, we solve the migration and C-REM models in a coupled fashion (Figure 2). In each time step, we use projected population of each province from the migration model as an input to

\footnotetext{
${ }^{6}$ For example, migrants originating in poor provinces may lack educational or professional skills relative to the labor force of the destination province, lowering the overall $\Omega$ of that province; working-age migrants who are more productive than the average local worker seeking employment may raise $S$ in the destination province.

${ }^{7}$ This assumption is unlikely to hold over a longer time horizon. The one-child policy, started in 1980, has resulted in an increasing proportion of the retired population over time. This effect will increase after 2020.
} 
C-REM, while the changes in GDP per capita computed in C-REM are used as an input to the migration model. After relocation, migrants are assumed to receive the new equilibrium average wage in the destination province, which ceteris paribus would tend to fall with an increase in the labor supply. We assume that provincial capital stocks are fixed within each time period.

Migrants are assumed to adopt the consumption patterns of residents in the destination province ${ }^{8}$. Out-migration provinces will see a reduction in both consumption and labor supply as a result of migration.

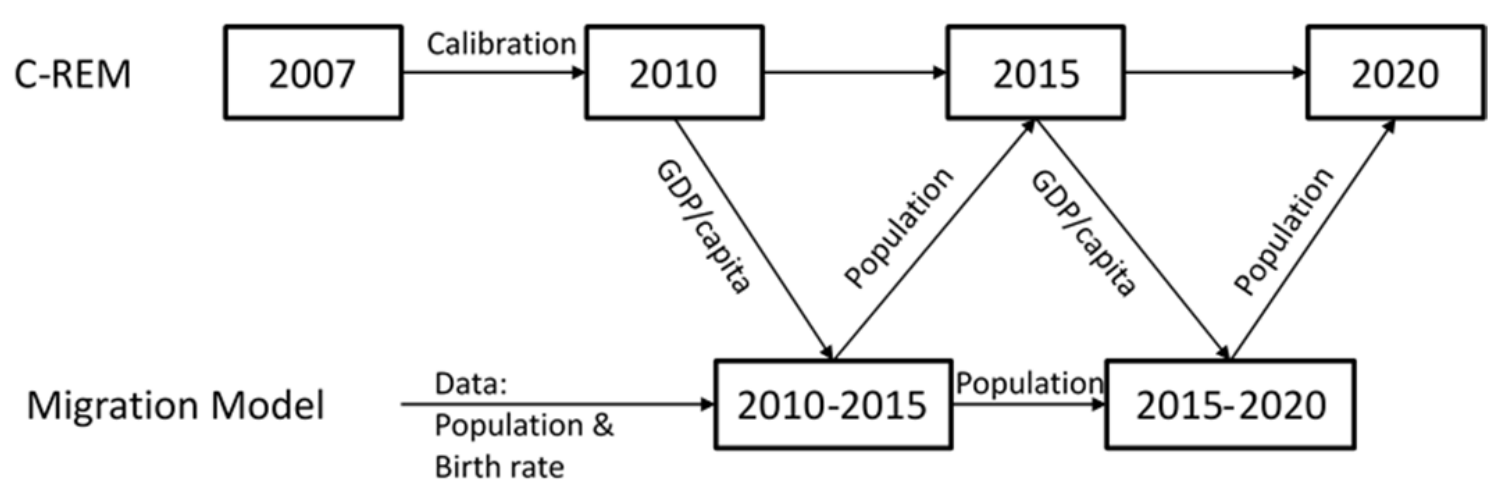

Figure 2. Coupling of the general equilibrium model (C-REM) and the migration model.

\section{RESULTS}

\subsection{Migration Projections}

Projected migration based on coupled runs of the C-REM and migration model is shown in Figure 3. Interestingly, despite historically observed rapid growth, the model simulates a peak in the total number of migrants at around 100 million from 2010-2015, with migration falling back to around 60 million from 2015-2020. This peak is largely explained by a decline in wage differentials between out- and in-migration provinces. Both historically and in the model projections, in-migration provinces experience lower and declining GDP growth, while out-migration provinces grow more rapidly. As wage differentials narrow, migration volumes decline. Figure A3 in the Appendix illustrates the negative relationship between average growth and net migration between 2005 and 2010. Population projections for all Chinese provinces are shown in the Appendix Table A1. Throughout the remainder of this paper, scenarios with migration include the migration projection in addition to natural population growth, while scenarios without migration include natural growth only.

According to our coupled model simulation, cumulative in-migration from 2010 to 2020 as a percentage of population (in 2010) is largest in Shanghai (SH, 39\%), Beijing (BJ, 38\%), and Zhejiang (ZJ, 33\%), while the largest out-migration is experienced in Hunan (HN, -22\%),

\footnotetext{
${ }^{8}$ There is no data available describing differences in consumption patterns between migrants and local consumers. While migrants' consumption patterns may well deviate from provincial averages, we expect that our assumption may tend to overestimate impacts on consumption, especially if migrants systematically secure lower-paying jobs and consume less relative to the provincial average.
} 
Jiangxi (JX, -22\%) and Anhui (AH, -20\%). Guangdong (GD, 33.95 million) receives the largest absolute number of migrants, while the origin of the largest number of migrants is Henan (HA, 13.68 million).

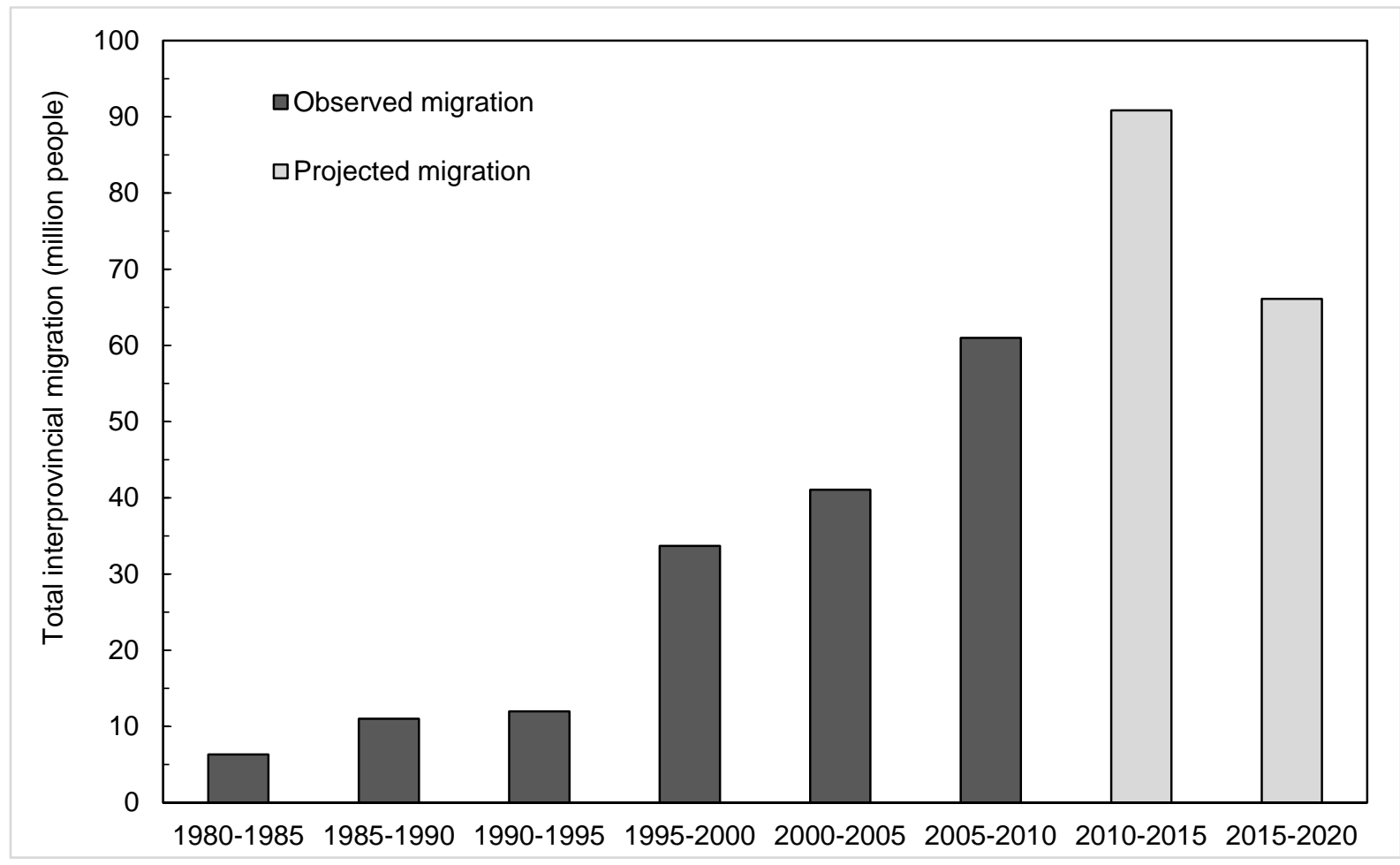

Figure 3. Total historical and projected migration (millions).

\subsection{Baseline Projection for GDP and Energy Use}

We develop two baseline (no policy) projections - one with migration (WM) and one with no migration (NM) to understand the influence of migration on the economy and energy use. Now and throughout the remainder of this report, we define energy use as the direct use of secondary energy (electricity, refined oil, gas and coal) in final demand (by households and the government) and as an input to industry. Table 3 reveals several effects of inter-provincial migration. First, migration increases the annual national GDP growth rate by approximately $0.1 \%$, as migrants tend to move to provinces with higher average productivity. We note, however, that this number is contingent on our assumption that migrants immediately adopt the average characteristics of their new province. We expect that this effect would be larger if migrants were unemployed or under-employed in their province of origin, but fully employed after migration. If migrants systematically contribute less than local laborers to the labor force (and consume less) in the destination province, the effect on GDP would be smaller (and could potentially disappear). The increase in GDP due to migration leads to an increase in income, and thus increases overall energy use. Finally, as migrants move to less energy intensive provinces, the national energy intensity decreases slightly. 
Table 3. Baseline economic and energy system outputs with migration (WM) and without migration (NM).

\begin{tabular}{llll}
\hline & $\mathbf{2 0 1 0}$ & $\mathbf{2 0 2 0}$ & $\mathbf{2 0 1 0 - 2 0 2 0 ~}$ \\
& Data & Projection & Annual growth rate \\
\hline GDP (bn\$ 2007 USD) & & & \\
$\begin{array}{l}\text { Without migration } \\
\begin{array}{l}\text { With migration } \\
\text { Energy use (Mtce) }\end{array}\end{array}$ & 5,148 & 9,680 & $6.52 \%$ \\
$\begin{array}{l}\text { Without migration } \\
\text { With migration }\end{array}$ & 5,148 & 9,761 & $6.61 \%$ \\
$\begin{array}{l}\text { Energy Intensity (Mtce/bn\$ 2007 USD) } \\
\text { Without migration }\end{array}$ & 3,296 & 5,800 & $5.81 \%$ \\
\begin{tabular}{l} 
With migration \\
\hline
\end{tabular} & 0.6402 & 5,845 & $5.90 \%$ \\
\hline
\end{tabular}

Modest changes at the national level mask heterogeneity across provinces. For example, in Table 4, we see that for the in-migration provinces Beijing (BJ) and Shanghai (SH), GDP is more than $17 \%$ higher with migration than without migration, and the energy use is more than 14\% higher. In the out-migration provinces, such as Anhui (AH) and Jiangxi (JX), with migration the GDP is more than 13\% lower and energy use is more than $4.5 \%$ lower than without migration. In general, while the effects of migration on GDP and energy use are correlated, it is of larger magnitude for GDP than energy use. The explanation for this is that most energy resources are located in the out-migration provinces. Because the location of fossil fuel extraction is fixed, and because frictions in the model limit rapid changes in the patterns of energy trade, the price elasticity of energy supply is fairly low in the out-migration provinces. This implies that the availability of energy does not directly follow the movement of migrants so that migration affects the availability of labor relative to energy.

This implies that energy supply does not fully adapt to the movement of migrants, so that migration affects the relative availability of labor and energy.

A larger labor force favors labor-intensive sectors, which also tend to be less energy intensive. In-migration provinces will increase their specialization in labor-intensive sectors, while outmigration provinces increase their specialization in energy-intensive sectors.

\footnotetext{
${ }^{9}$ Mega tons of Coal Equivalent
} 
Table 4. GDP, energy use and energy intensity change with migration relative to no migration in 2020.

\begin{tabular}{|c|c|c|c|}
\hline Provinces & GDP change (\%) & Energy use change (\%) & Energy intensity change (\%) \\
\hline Guizhou & -13.7 & -0.8 & 14.9 \\
\hline Jiangxi & -13.3 & -4.6 & 10.0 \\
\hline Anhui & -13.2 & -4.8 & 9.7 \\
\hline Hunan & -12.6 & -5.2 & 8.5 \\
\hline Chongqing & -11.2 & -2.1 & 10.2 \\
\hline Sichuan & -10.9 & -4.0 & 7.7 \\
\hline Henan & -10.8 & -4.4 & 7.2 \\
\hline Hubei & -10.3 & -6.5 & 4.2 \\
\hline Guangxi & -8.3 & -2.8 & 6.0 \\
\hline Gansu & -6.9 & -2.9 & 4.3 \\
\hline Heilongjiang & -6.9 & -5.0 & 2.0 \\
\hline Jilin & -4.3 & -0.8 & 3.7 \\
\hline Hebei & -3.0 & 0.3 & 3.4 \\
\hline Shaanxi & -2.9 & 0.1 & 3.1 \\
\hline Shanxi & -2.6 & -1.6 & 1.0 \\
\hline Yunnan & -2.6 & -1.2 & 1.4 \\
\hline Shandong & -2.3 & -0.7 & 1.6 \\
\hline Qinghai & 0.4 & 0.5 & 0.1 \\
\hline Liaoning & 1.4 & 1.4 & 0.0 \\
\hline Inner Mongolia & 2.4 & 1.3 & -1.1 \\
\hline Ningxia & 3.1 & 2.6 & -0.5 \\
\hline Xinjiang & 3.1 & 5.0 & 1.8 \\
\hline Hainan & 3.6 & 1.0 & -2.5 \\
\hline Jiangsu & 5.4 & 3.4 & -1.9 \\
\hline Fujian & 6.1 & 4.1 & -1.9 \\
\hline Guangdong & 13.3 & 8.9 & -3.9 \\
\hline Zhejiang & 15.2 & 13.0 & -1.9 \\
\hline Shanghai & 17.3 & 14.3 & -2.6 \\
\hline Tianjin & 18.3 & 8.0 & -8.7 \\
\hline Beijing & 18.6 & 15.1 & -3.0 \\
\hline
\end{tabular}


Figure 4 shows the negative relationship between net in-migration and energy intensity across provinces in the data, and we observe that net in-migration provinces are on average less energy-intensive. Figure 5 displays differences in sectorial output with migration (relative to no migration) in both in-migration and out-migration provinces. ${ }^{10}$ It reveals a disproportionately large increase in the services sector of the in-migration provinces relative to the increase in energy production and the output of energy intensive industries. Output of energy intensive industries does not decrease as much in the out-migration provinces, and their production of fossil fuel energy actually increases. Similarly, households in the out-migration provinces will increase their consumption of energy. Overall, migration tends to increase the energy intensity of the net out-migration provinces and decrease that of in-migration provinces. Figure 6 shows the relationship between migration and change in energy intensity by province.

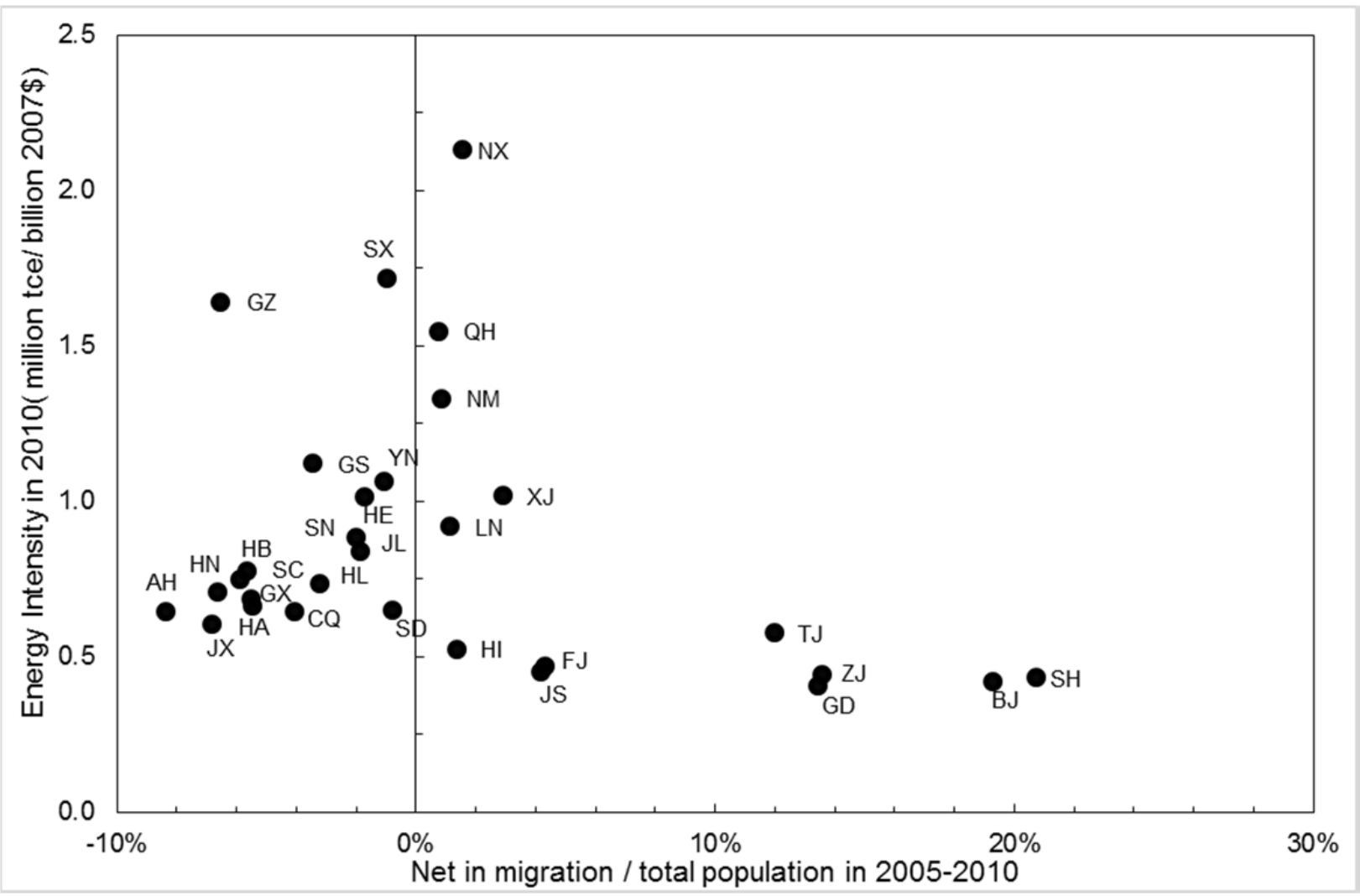

Figure 4. Relationship between net in-migration and energy intensity across provinces.

\footnotetext{
${ }^{10}$ Grouped according to net in or out migration in Figure 1. FFP corresponds to primary fossil production and is the
} aggregate of COL, OIL, CRU and GAS. 


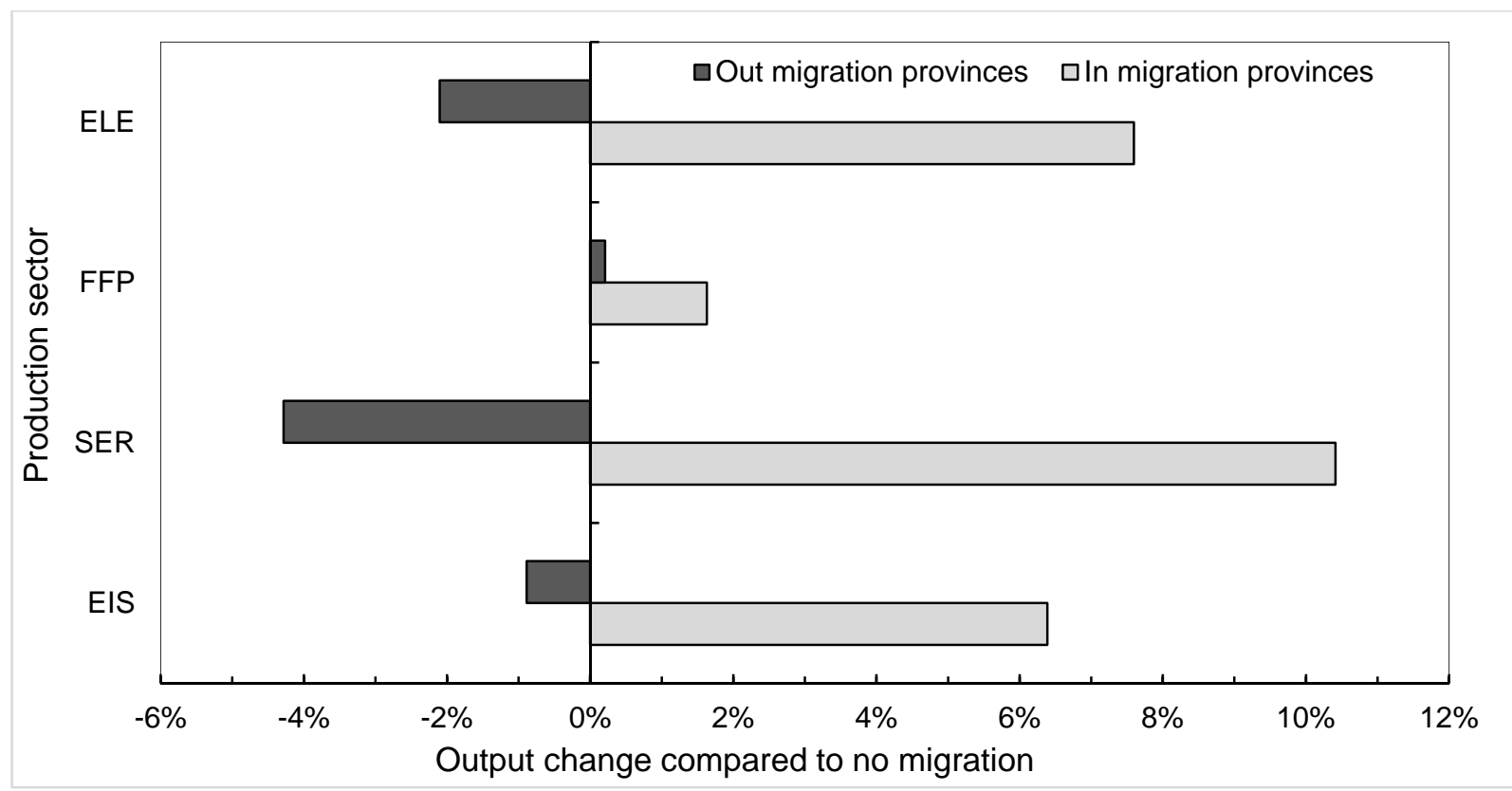

Figure 5. The weighted average changes in sectorial output caused by migration in in-migration and out-migration province groups.

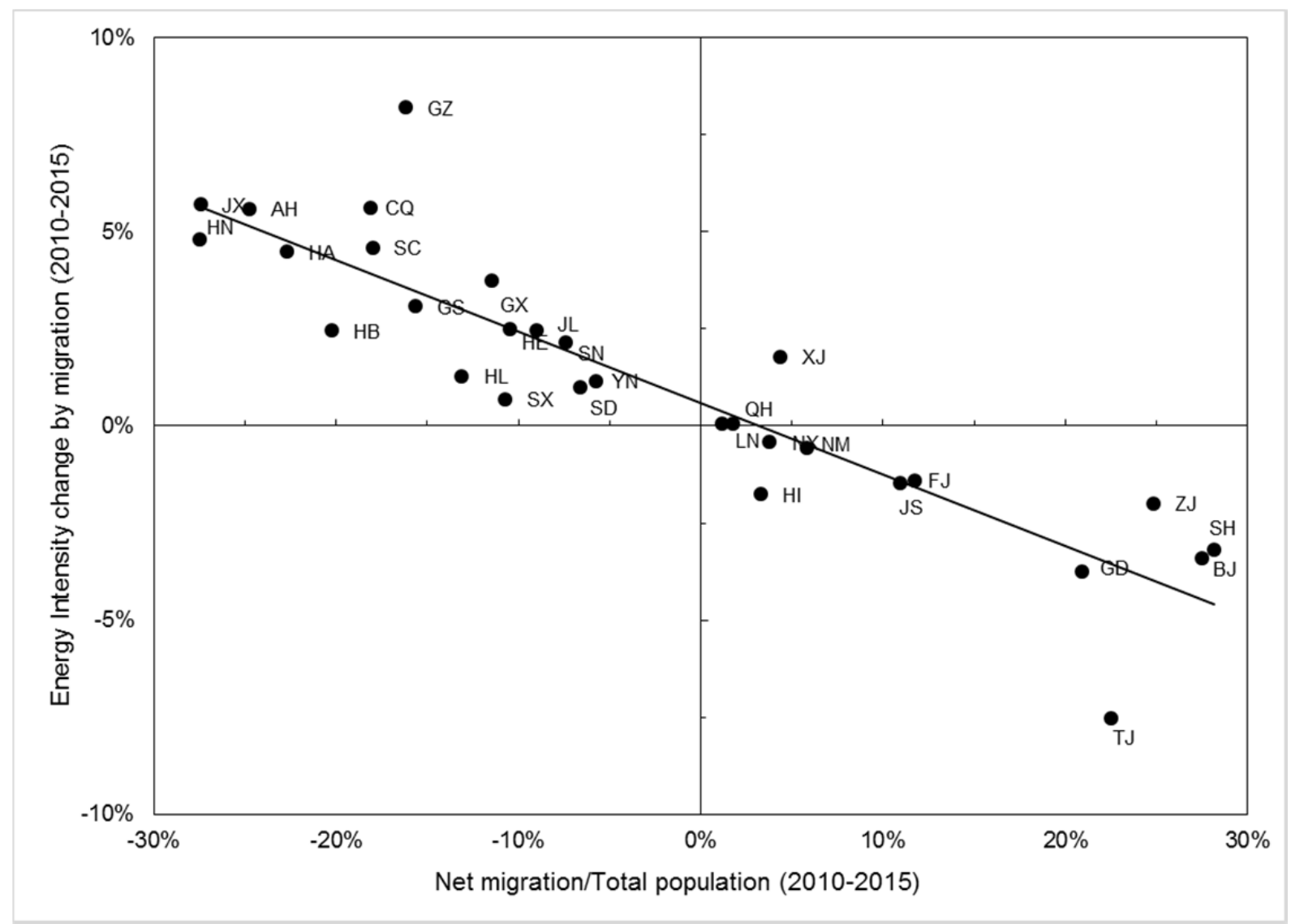

Figure 6. Projected net migration against projected change in energy intensity (2010-2015). 
We illustrate the impact of migration using two provinces, Shanghai and Anhui, as an example. Migration flows between Shanghai and Anhui rank among the largest in China at around 1.7 million people from 2006 to 2010, as many migrants leave Anhui, a relatively poor area, for Shanghai, one of the most affluent centers of commerce on the Chinese mainland. As shown in Table 5, our simulations reveal that migration contributes 1.6 percentage points to Shanghai's annual GDP growth rate, which was 4.6\% for the simulation period 2010-2020. Higher growth also leads to an increase in energy use, though it is proportionally lower than the project growth in GDP. This example shows how failing to consider migration would lead policymakers to underestimate the absolute increase in energy use in Shanghai. If an energy cap is set without considering migration, the burden on Shanghai could be larger than expected. By contrast, failing to consider migration policymakers would lead to underestimation of the projected reduction in energy intensity; therefore, energy intensity targets would place less of a burden on in-migration provinces like Shanghai.

Table 5. GDP and energy use of Shanghai and Anhui at baseline.

\begin{tabular}{|c|c|c|c|c|c|}
\hline \multirow[b]{2}{*}{$\begin{array}{l}\text { GDP } \\
(2007 \mathrm{bn} \$)\end{array}$} & \multirow[b]{2}{*}{$\begin{array}{l}2010 \\
\text { Data }\end{array}$} & \multicolumn{2}{|c|}{ No Migration (NM) } & \multicolumn{2}{|c|}{ With Migration (WM) } \\
\hline & & $\begin{array}{l}2020 \\
\text { Projection }\end{array}$ & $\begin{array}{l}\text { 2010-2020 } \\
\text { Annual growth rate }\end{array}$ & $\begin{array}{l}2020 \\
\text { Projection }\end{array}$ & $\begin{array}{l}\text { 2010-2020 } \\
\text { Annual growth rate }\end{array}$ \\
\hline Shanghai & 213.7 & 288.2 & $3.0 \%$ & 336.1 & $4.6 \%$ \\
\hline Anhui & 140.0 & 300.6 & $7.9 \%$ & 274.6 & $7.0 \%$ \\
\hline \multicolumn{6}{|c|}{ Energy use (Mtce) } \\
\hline Shanghai & 95.9 & 138.2 & $3.7 \%$ & 156.0 & $5.0 \%$ \\
\hline Anhui & 84.7 & 154.7 & $6.2 \%$ & 149.2 & $5.8 \%$ \\
\hline \multicolumn{6}{|c|}{ Energy Intensity } \\
\hline Shanghai & 0.449 & 0.479 & $0.7 \%$ & 0.464 & $0.3 \%$ \\
\hline Anhui & 0.605 & 0.514 & $-1.6 \%$ & 0.543 & $-1.1 \%$ \\
\hline
\end{tabular}

\subsection{Policy Simulation}

The remainder of our analysis is focused on understanding how energy policy outcomes in China will be affected by future migration flows. We compare energy caps and energy intensity targets, two prevalent policy designs under consideration in China, to be set at the provincial level with the aim of achieving an overall national target. In the real world, the mechanism for enforcing targets at the provincial level is a complex combination of administrative intervention measures such as forced retirement of small power plants and low energy efficiency steel production capacities, market-based instruments such as subsidy and bonus for energy savings, and auxiliary means such as information campaigns (Qi 2013).

Within our model, energy caps and energy intensity targets are implemented as a constraint on total energy or energy intensity that is achieved by endogenously increasing the price of energy to a level that results in target compliance, as in Zhang et al. (2013). Specifically, we target the direct use of secondary energy. 
In order to identify the effect of migration on compliance with energy quantity and energy intensity targets, we designed a no-migration scenario in which the outcomes of both policies are identical by construction. With migration, these two policies will have different effects. This allows us to focus on the deviations caused by introducing migration.

We thus simulate the following scenarios:

- Energy Cap / Energy Intensity Policies without Migration (ENM). We set energy intensity targets to achieve a level of energy intensity reduction consistent with China's Twelfth Five-Year Plan (2011-2015), and extended it for the Thirteenth Five-Year Plan (2016-2020) at the same level of stringency. Energy intensity targets, $i_{r}^{\text {targ }}=$ $X_{r} / G D P_{r}$, correspond to the ratio of secondary energy use in province $r, X_{r}$, and provincial value-added, $G D P_{r}$. The targeted reductions in intensity, $100 \times\left(i_{r}-\right.$ $\left.i_{r}^{\text {targ }}\right) /{ }^{\prime} i_{r}$ can be found in Table A2 of the Appendix. The average energy intensity reduction target is $15.7 \%$ with a standard deviation of $2.1 \%$. Nationally, targets correspond to a $16 \%$ reduction in energy intensity. This policy can also be interpreted as an energy cap policy in which energy demand targets, $X_{r}^{\operatorname{targ}}=i_{r}^{\operatorname{targ}} \times G D P_{r}$, are constructed using the intensity targets and the implied level of economic activity. As such, this scenario is designed such that both policies produce identical outcomes in the absence of changes in migration or economic growth assumptions.

- Energy Cap Policy with Migration (ECM). The energy cap described by the quantity targets defined in the ENM scenario are implemented. The only difference is that migration is simulated.

- Energy Intensity Policy with Migration (EIM). The energy intensity policy described for the ENM scenario is implemented. The only difference is that migration is simulated.

In line with literature focusing on policy robustness (Anderies et al. 2013), we consider the robustness of these two policies by measuring how well the effective distribution of burden across provinces (expressed in terms of welfare loss) matches the intention of policy makers. Then, we compare their relative efficiency in terms of reducing energy use at minimal cost.

To investigate robustness, we compare welfare impacts of the ECM and EIM scenarios to the ENM scenario, which provides a suitable benchmark and represents consensus on the distribution of policy burdens embodied in the Twelfth Five-Year Plan. To do so, we define a welfare impact index $K_{S, r}$ to quantify the percentage change of the welfare loss of scenario $S$ ( $S$ being either ECM or EIM) compared to the policy maker's expectation:

$$
K_{S, r}=\left(\frac{\left|\Delta W_{S, r}\right|}{\left|\Delta W_{E N M, r}\right|}-1\right)=\left(\frac{\left|W_{S, r} / W_{W M, r}-1\right|}{\left|W_{E N M, r} / W_{N M, r}-1\right|}-1\right)
$$

In Equation 5, $W_{S, r}$ is the welfare implied by scenario $S$ in province $r$. Therefore, $\Delta W_{S, r}=W_{S, r} / W_{W M, r}-1$ and $\Delta W_{E N M, r}=W_{E N M, r} / W_{N M, r}-1$ represent the welfare change of 
province $r$ under the $S$ scenario and scenario ENM, respectively. Hence, index K corresponds to the ratio of the welfare change which we predict will occur (with migration), relative to the welfare change that would have occurred without migration.

We then build a robustness index $R_{S}$, which quantifies the overall deviations of provincial welfare changes compared to those of the ENM scenario. It corresponds to the weighted average absolute deviation of welfare changes and is computed as follows:

$$
R_{S}=\sum_{r} \frac{c_{r}}{\sum_{r} c_{r}}\left|K_{S, r}\right|
$$

In Equation 6, $c_{r}$ is the consumption level of province $r$ under the ENM scenario. Hence, $R_{S}$ quantifies the weighted average deviation of welfare changes under the $S$ scenario compared to the ENM scenario. The smaller the $R_{S}$, the more robust the policy is. Quantitatively, we estimate $R_{E C M}$ to be $24.5 \%$ - significantly higher than $R_{E I M}$, which we find to be $15.8 \%$. Energy intensity targets are more robust and better reflect the distribution of burden intended by the policy makers, but they still fail to do so entirely.

Figure 7 displays the impact of migration on the welfare change index $K_{S, r}$ for each province. For example, the value of $\mathrm{K}$ for Guangxi (GX) in the ECM scenario is $180 \%$. This means that we find that energy caps will be $180 \%$ more costly in Guangxi than what one would find if we ignored migration. The ECM scenario generates larger deviations in general, especially for major in-migration provinces, such as Beijing and Shanghai. On top of this difference in magnitude, the patterns of deviations between ECM and EIM are almost opposite. By underestimating the positive impact of migration on their total GDP and energy use, the energy cap puts a greater burden on the in-migration provinces; by underestimating the increase in their energy intensity, the energy intensity policy puts a greater burden on the out-migration provinces. 


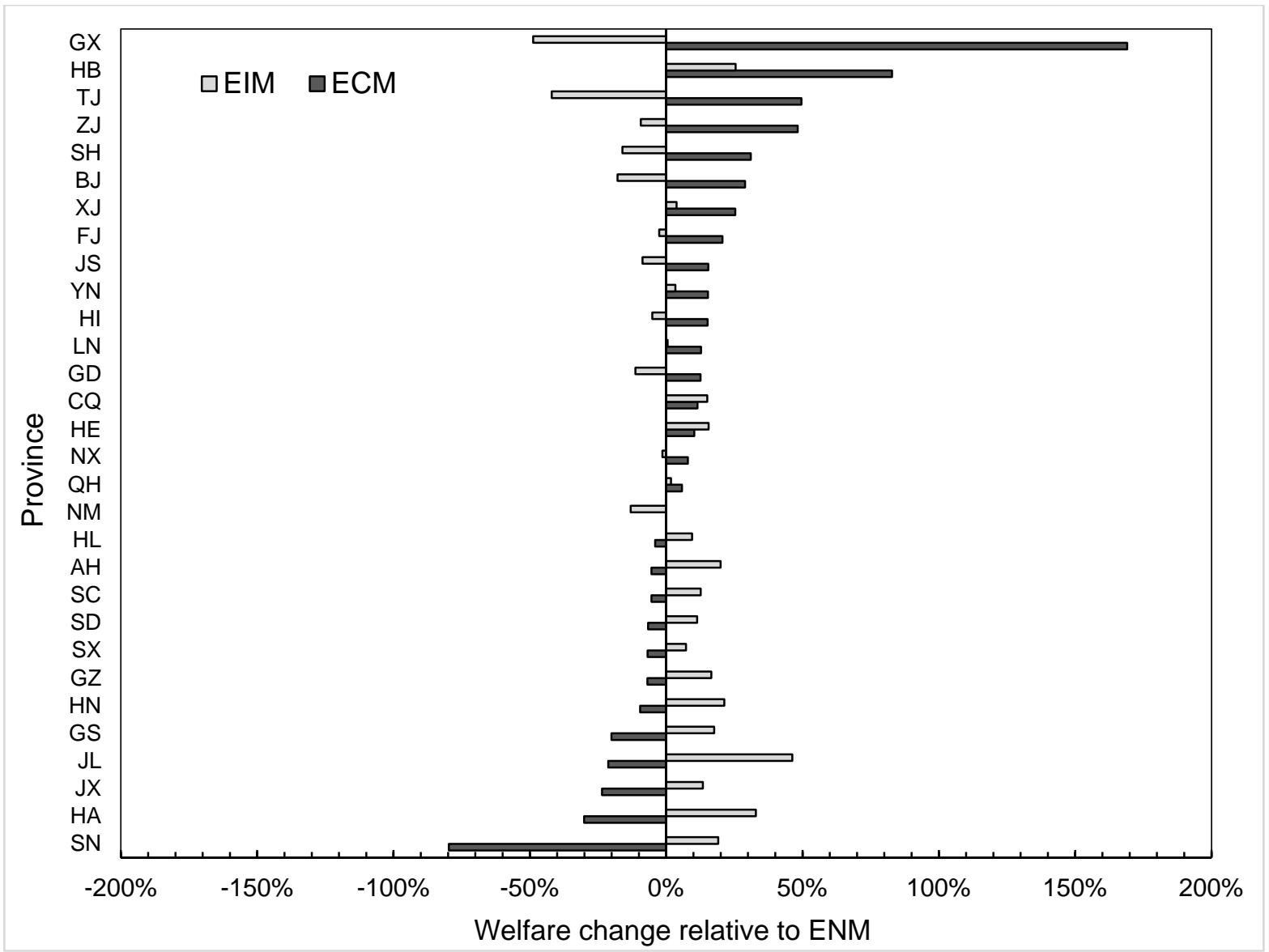

Figure 7. Welfare impact of migration $\left(K_{S, r}\right)$ in percentage relative to no migration (ENM) scenario across provinces. Positive value indicates that policy will increase welfare relative to the ENM case.

Because each policy puts the burden of energy use reduction on different provinces, they will lead to different overall costs and total energy use. It is cheaper to reduce energy use in the out-migration provinces, as more efficient production processes have already been widely applied in the more developed, lower energy intensity in-migration provinces in the east (see Figure 5). This is made evident by comparing the average shadow price of energy use reduction in the in-migration provinces to the average shadow price of out-migration provinces. In the ENM scenario, the average shadow price of the energy policy in out-migration provinces is $\$ 50$ per ton of coal equivalent (tce), while it is $\$ 190 /$ tce for in-migration provinces. The energy cap policy puts more burden on in-migration provinces in which energy reductions are costlier and thus leads to higher GDP and welfare losses than the energy intensity policy. National results for the three scenarios are summarized in Table 6. All changes in the table are expressed relative to the corresponding no policy scenario (that is, the ENM scenario is expressed relative to the NM baseline scenario, whereas the ECM and EIM scenarios are expressed relative to the WM baseline scenario). In the absence of migration (ENM), national welfare loss reaches $1.69 \%$ of consumption (measured as equivalent variation) in 2020. With migration, consumption loss is 
20\% higher than ENM under the energy cap (ECM) and only 5\% higher under the energy intensity policy (EIM).

Table 6. National GDP, energy use and welfare change by policies (\% change).

\begin{tabular}{llllllll}
\hline Year & \multicolumn{3}{c}{2015} & & \multicolumn{3}{c}{2020} \\
\cline { 2 - 3 } \cline { 6 - 8 } Scenarios & ENM & ECM & EIM & & ENM & ECM & EIM \\
\hline GDP & -0.58 & -0.66 & -0.65 & & -2.35 & -2.62 & -2.47 \\
\hline Energy use & -12.28 & -13.20 & -13.27 & & -24.91 & -25.49 & -26.12 \\
Welfare & -0.42 & -0.55 & -0.44 & & -1.69 & -2.02 & -1.78 \\
\hline Energy intensity & -11.76 & -12.61 & -12.71 & & -23.09 & -23.48 & -24.24 \\
\hline
\end{tabular}

ENM: Energy cap/intensity policy without migration; ECM: Energy cap policy with migration; EIM: Energy intensity policy with migration.

The policies also have different effects on total national energy use. For ECM, more stringent energy use reduction targets in the in-migration provinces cause relocation of energy intensive industries to the out-migration provinces. For EIM, because the energy resources are mostly located in the out-migration provinces, the potential for relocation of energy-intensive industries is much smaller when larger reductions are expected from the out-migration provinces. Overall, Table 6 shows that the EIM policy leads to a larger reduction in total energy use than the energy cap, and indeed, we find that net embodied emissions in domestic trade from out-migration provinces to in-migration provinces ${ }^{11}$ are significantly higher in the ECM scenario (see Figure 8). Together, these results indicate that, in the face of migration, energy intensity targets lead to a higher reduction in energy use at lower cost (lower GDP and welfare loss) and are therefore more efficient overall than provincial energy caps.

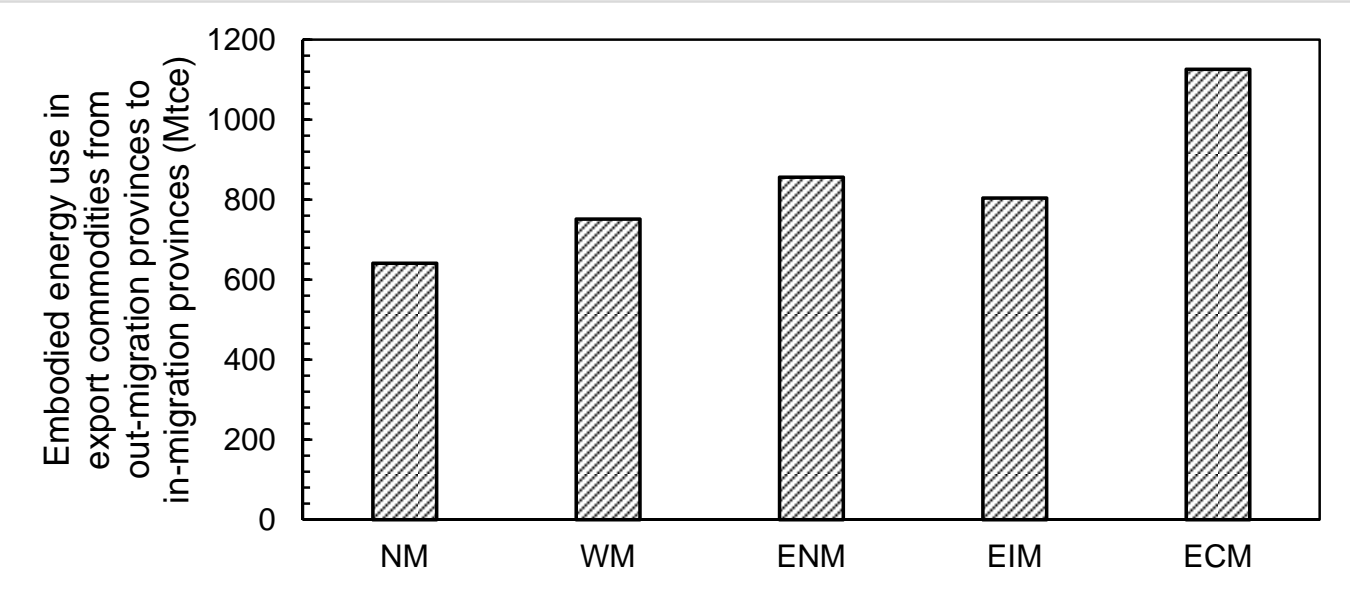

Figure 8. Embodied energy use in export commodities from out-migration provinces to in-migration provinces.

\footnotetext{
${ }^{11}$ Calculated using a multi-regional input-output decomposition as in Böhringer et al. (2012).
} 


\section{CONCLUSION}

Using a newly developed coupled modeling approach to represent the macroeconomic and energy impacts of migration within a CGE framework, we show that if policies are to be set at the provincial level, energy intensity targets are both more efficient and more robust to uncertain levels of migration than energy caps. Although the amount of interprovincial migration in China is very large and will maintain its momentum for several more years, our model projects that it will peak before 2020, as wage differentials between province pairs will then decrease. Though migration has minor impacts on the growth of GDP and energy use at the national level, provincial changes could be significant. For example, major eastern in-migration provinces (e.g. Beijing and Shanghai) will increase their output, largely due to more abundant labor supply. Energy use, however, is not projected to increase as rapidly for in-migration provinces-nor decrease as rapidly in out-migration provinces-as GDP. Thus, migration will further increase the relative energy-intensity of out-migration provinces relative to in-migration provinces.

Our analysis shows how migration can affect the implementation of energy policy by changing both relative factor endowments as well as the consumption profile of individual provinces. If energy policy is set at the provincial level without built-in mechanisms to adjust targets based on quantities most affected by these uncertainties - such as economic productivity and energy intensity —inevitably some provinces will find it easier to meet the overall targets than others, with implications about welfare losses. Moreover, energy policy could further contribute to regional disparities as tightly constrained in-migration provinces face ever-stronger incentives to outsource production to out-migration provinces in order to meet provincial limits.

Our work also points to a broader set of uncertainties that may affect the cost effectiveness of provincial energy policy. Here, we focus only on the "net migration" between province pairs, but we do not explicitly consider urbanization that may occur within provinces, potentially with important implications for the efficiency and structure of energy use (O'Neill et al. 2012). The interaction of urbanization with provincial energy targets is a fruitful area for future research.

If China remains in a provincial policy paradigm — which is likely, given China's well-established institutional environment that enlists provincial governments in the local implementation of national policy directives - an energy intensity target is favorable to an energy cap for both efficiency and robustness measures. However, this result holds only if targets are set province-by-province, with no opportunity to equalize marginal costs across geographies. Policy instruments that bind at the national rather than provincial level would reduce energy use in provinces where it costs least and respond to changes in the ranking of cost-effective reduction opportunities caused by migration. Therefore, while an energy intensity target is found to be superior to a cap in the provincial policy paradigm, a national intensity target or a national energy cap would both be uniformly superior. This finding provides strong impetus for China's policymakers to continue efforts to establish a national $\mathrm{CO}_{2}$ emissions trading system. 
We gratefully acknowledge the support of the National Social Science Foundation of China (09\&ZD029). This research is further supported by Eni S.p.A., the French Development Agency (AFD), ICF International, and Shell International Limited, founding sponsors of the MIT-Tsinghua China Energy and Climate Project. We thank the MIT Joint Program on the Science and Policy of Global Change for providing support through a consortium of industrial sponsors and U.S. federal grants.

\section{REFERENCES}

Anderies, J.M., C. Folke, B. Walker and E. Ostrom, 2013: Aligning Key Concepts for Global Change Policy: Robustness, Resilience, and Sustainability, Ecology and Society 18(2).

Auffhammer, M. and R.T. Carson, 2008: Forecasting the Path of China's $\mathrm{CO}_{2}$ Emissions Using Province-Level Information, Journal of Environmental Economics and Management 55(3): 229-47.

Böhringer, C., B. Bye, T. Fæhn and K.E. Rosendahl, 2012: Alternative Designs for Tariffs on Embodied Carbon: A Global Cost-Effectiveness Analysis, Energy Economics 34: S143-S153.

Böhringer, C., and T.F. Rutherford, 2009: Integrated Assessment of Energy Policies: Decomposing Top-down and Bottom-Up, Journal of Economic Dynamics and Control 33(9): 1648-61.

Cao, J., 2007: Essays on Environmental Tax Policy Analyses: Dynamic Computable General Equilibrium Approaches Applied to China, Harvard University (http://gradworks.umi.com/32/64/3264920.html).

Cao, J. and M.S. Ho, 2010: Changes in China's Energy Intensity: Origins and Implications for Long-Term Carbon Emissions and Climate Policies (http://ideas.repec.org/p/eep/report/rr2010126.html).

Caron, J., S. Rausch and N. Winchester, 2015: Leakage from Sub-National Climate Policy: The Case of California's Cap-and-Trade Program, Energy Journal 36(2)

China State Council, 2011: Work Plan for 'Twelfth-Five-Year' Energy Reduction.

Cui, L.-B., Y. Fan, L. Zhu and Q.-H. Bi, 2014: How Will the Emissions Trading Scheme Save Cost for Achieving China's 2020 Carbon Intensity Reduction Target? Applied Energy, in press.

Dai, H., T. Masui, Y. Matsuoka and S. Fujimori, 2011: Assessment of China's Climate Commitment and Non-Fossil Energy Plan towards 2020 Using Hybrid AIM/CGE Model, Energy Policy 39(5): 2875-87.

Dustmann, C., 2003: Return Migration, Wage Differentials, and the Optimal Migration Duration, European Economic Review 47: 353-69.

Flaig, D., H. Grethe and S. Mcdonald, 2013: Imperfect Labour Mobility in a CGE Model: Does Factor Specific Productivity Matter? GTAP 2013 Conference Paper.

Flowerdew, R. and M. Aitkin, 1982: A Method of Fitting the Gravity Model Based on the Poisson Distribution, Journal of Regional Science 22(2): 191-202.

Guan D., Z. Liu, Y. Geng, S. Lindner and K. Hubacek, 2012: The gigatonne gap in China's carbondioxide inventories. Nature Climate Change 2: 672-5. 
Guangdong Statistic Bureau, 2011: Guangdong $12^{\text {th }}$ Five Year Plan (http://zwgk.gd.gov.cn/006939748/201105/t2011051386534.html).

Hu, D., 2002: Trade, Rural-urban Migration, and Regional Income Disparity in Developing Countries: A Spatial General Equilibrium Model Inspired by the Case of China, Regional Science and Urban Economics 32(3): 311-38.

Hua, C. and F. Porell, 1979: A Critical Review of the Development of the Gravity Model, International Regional Science Review 4(2): 97-126.

Kau, J.B. and C.F. Sirmans, 1979: A Recursive Model of the Spatial Allocation of Migrants, Journal of Regional Science 19(1): 47-56.

Laitner, J. and D. Hanson, 2006: Modeling Detailed Energy-Efficiency Technologies and Technology Policies within a CGE Framework, The Energy Journal 151-70.

Li, K., 2013: Promoting Coordinated Urbanization - an Important Strategic Choice for Achieving Modernization (http://www.primeeconomics.org/wp-content/uploads/2013/06/LiKeqiang-China-urbanization-speech.pdf).

Liang, Q. and Y. Wei, 2012: Distributional Impacts of Taxing Carbon in China: Results from the CEEPA Model, Applied Energy 92(0): 545-51.

Lin, B. and Z. Jiang, 2011: Estimates of Energy Subsidies in China and Impact of Energy Subsidy Reform. Energy Economics 33(2): 273-83.

Lipton, M., 1980: Migration from Rural Areas of Poor Countries: The Impact on Rural Productivity and Income Distribution, World Development 8(1): 1-24.

Ma, W. and Y. Wang, 2012: Transportation Infrastructure and Population Migration in China: An Analysis Based on Gravity Model, China Soft Science 3(009).

Michael, M.S., 2003: International Migration, Income Taxes and Transfers: A Welfare Analysis, Journal of Development Economics 72(1): 401-11.

NBS (National Bureau of Statistics of China), 2012: China Statistical Database, National Bureau of Statistics of the People's Republic of China (http://www.stats.gov.cn/english/Statisticaldata).

O’Neill, B.C., X. Ren, L. Jiang and M. Dalton, 2012: The Effect of Urbanization on Energy Use in India and China in the iPETS Model, Energy Economics 34: S339-S345.

Paltsev, S., J.M. Reilly, H.D. Jacoby, R.S. Eckaus, J. McFarland, M. Sarofim, M. Asadoorian and M. Babiker, 2005: The MIT Emissions Prediction and Policy Analysis (EPPA) Model: Version 4, MITJPSPGC Report 125, August, 72 p. (http://globalchange.mit.edu/files/document/MITJPSPGC_Rpt125.pdf).

Qi. Y. 2013: Annual Review of Low-carbon Development in China: 2013. Social Sciences Academic Press. Beijing.

Rausch, S., G.E. Metcalf and J.M. Reilly, 2011: Distributional Impacts of Carbon Pricing: A General Equilibrium Approach with Micro-Data for Households, Energy Economics 33, Supple (0): S20-33.

Ravenstein, E.G., 1885: The Laws of Migration, Journal of the Statistical Society of London 48(2): 167-235.

Rutherford, T.F., 2001: A General Equilibrium Model for Tax Policy Analysis in Colombia (http://www.mpsge.org/dnp2001.pdf). 
Shen, J., 2013: Increasing Internal Migration in China from 1985 to 2005: Institutional versus Economic Drivers, Habitat International 39: 1-7.

Simini, F., M.C. González, A. Maritan and A.-L. Barabási, 2012: A Universal Model for Mobility and Migration Patterns, Nature 484(7392): 96-100 (http://www.ncbi.nlm.nih.gov/pubmed/22367540).

Tang, W. and L. Wu, 2013: Efficiency or Equity? Simulating the Carbon Emission Permits Trading Schemes in China Based on an Inter-Regional CGE Model, in The $16^{\text {th }}$ Annual Conference on Global Economic Analysis.

UN (United Nations), 2011: World Population Prospects: The 2010 Revision (http://esa.un.org/wpp/documentation/pdf/WPP2010_Volume-I_Comprehensive-Tables.pdf).

Wang, K, C. Wang and J. Chen, 2009: Analysis of the Economic Impact of Different Chinese Climate Policy Options Based on a CGE Model Incorporating Endogenous Technological Change, Energy Policy 37(8): 2930-40.

Wang, X., J.F. Li and Y.X. Zhang, 2011: An Analysis on the Short-Term Sectoral Competitiveness Impact of Carbon Tax in China, Energy Policy 39(7): 4144-52.

Wei, C., 2012: Regional Allocation of Carbon Dioxide Abatement in China, China Economic Review 23(3): 552-65.

Westerlund, J. and F. Wilhelmsson, 2011: Estimating the Gravity Model without Gravity Using Panel Data, Applied Economics 43(6): 641-49.

Whalley, J. and S. Zhang, 2007: A Numerical Simulation Analysis of (Hukou) Labour Mobility Restrictions in China, Journal of Development Economics 83(2): 392-410.

Xinhua Net, 2009: China's Green Policy Lauded at UN Climate Summit, Xinhua Net (http://news.xinhuanet.com/english/2009-09/23/content_12103241.htm).

Yi, W., 2011: How Can China Reach Its $\mathrm{CO}_{2}$ Intensity Reduction Targets by 2020? A Regional Allocation Based on Equity and Development, Energy Policy 39(5): 2407-15.

Zhang, D., S. Rausch, V.J. Karplus and X. Zhang, 2013: Quantifying Regional Economic Impacts of $\mathrm{CO}_{2}$ Intensity Targets in China, Energy Economics 40: 687-701.

Zhao, S. and X. Meng, 1999: Leaving the Countryside: Rural-to-Urban Migration Decisions in China, American Economic Review 89(2).

Zhu, N., 2002: The Impacts of Income Gaps on Migration Decisions in China, China Economic Review 13(2-3): 213-30.

Zipf, G.K., 1946: The P1 P2/D Hypothesis: On the Intercity Movement of Persons, American Sociological Review 11(6): 677-86. 


\section{APPENDIX}

Table A1. Projection of populations by province (millions of people). ${ }^{12}$

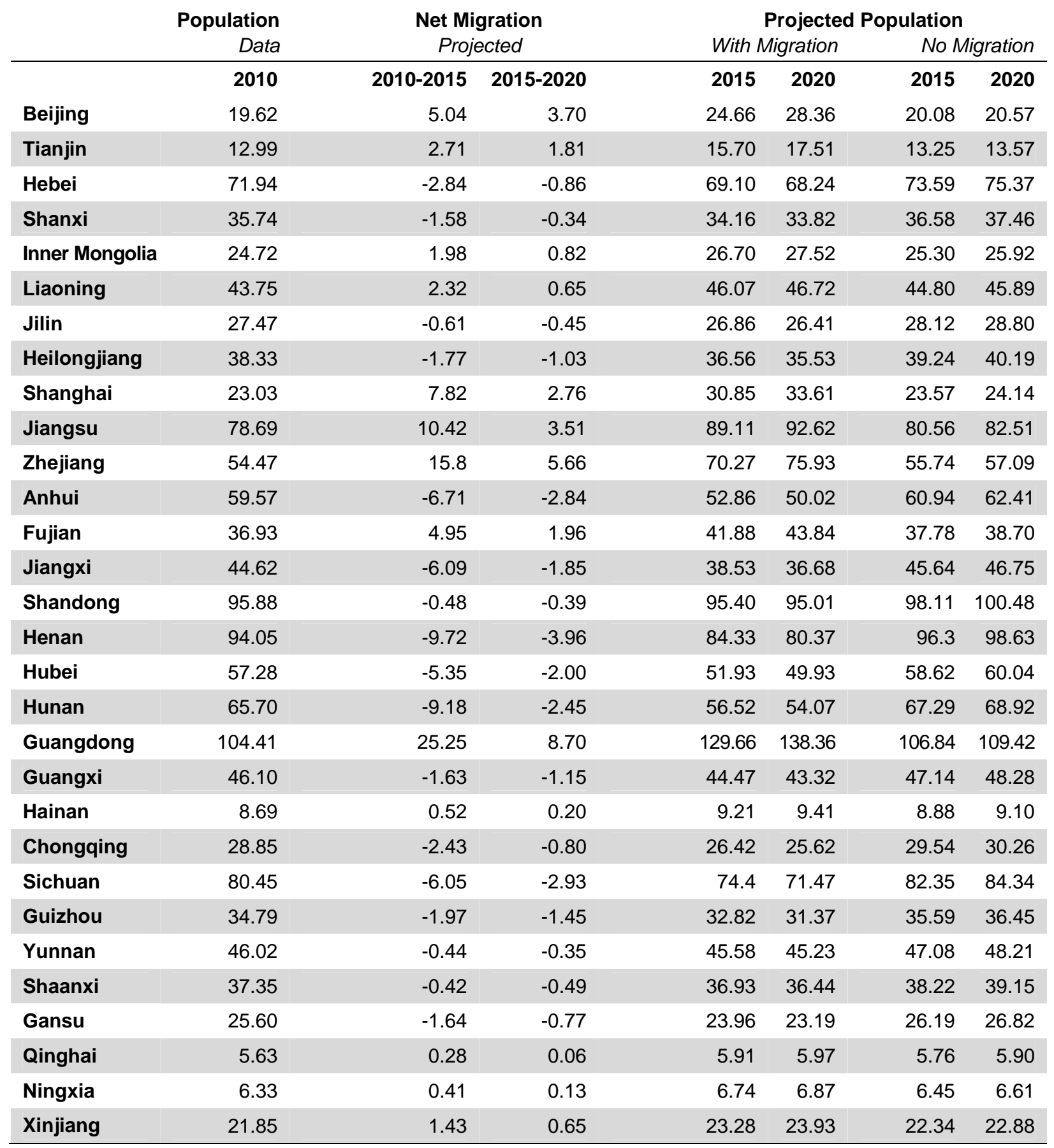

${ }^{12}$ The prediction of population is based on the economic model as well; therefore the population prediction will be different in each scenario. This is the baseline prediction. 
Table A2. Energy intensity reduction target (\%) allocation of $11^{\text {th }}, 12^{\text {th }}, 13^{\text {th }}$ FYP.

\begin{tabular}{|c|c|c|c|}
\hline & $\begin{array}{l}11^{\text {th }} \text { FYP } \\
2006-2010\end{array}$ & $\begin{array}{l}12^{\text {th }} \text { FYP } \\
2011-2015\end{array}$ & $\begin{array}{l}13^{\text {th }} \text { FYP } \\
2016-2020\end{array}$ \\
\hline Beijing & 26.59 & 17 & 17 \\
\hline Tianjin & 21 & 18 & 18 \\
\hline Hebei & 20.11 & 17 & 17 \\
\hline Shanxi & 22.66 & 16 & 16 \\
\hline Inner Mongolia & 22.62 & 15 & 15 \\
\hline Liaoning & 20.01 & 17 & 17 \\
\hline Jilin & 22.04 & 16 & 16 \\
\hline Heilongjiang & 20.79 & 16 & 16 \\
\hline Shanghai & 20 & 18 & 18 \\
\hline Jiangsu & 20.45 & 18 & 18 \\
\hline Zhejiang & 20.01 & 18 & 18 \\
\hline Anhui & 20.36 & 16 & 16 \\
\hline Fujian & 16.45 & 16 & 16 \\
\hline Jiangxi & 20.04 & 16 & 16 \\
\hline Shandong & 22.09 & 17 & 17 \\
\hline Henan & 20.12 & 16 & 16 \\
\hline Hubei & 21.67 & 16 & 16 \\
\hline Hunan & 20.43 & 16 & 16 \\
\hline Guangdong & 16.42 & 18 & 18 \\
\hline Guangxi & 15.22 & 15 & 15 \\
\hline Hainan & 12.14 & 10 & 10 \\
\hline Chongqing & 20.95 & 16 & 16 \\
\hline Sichuan & 20.31 & 16 & 16 \\
\hline Guizhou & 20.06 & 15 & 15 \\
\hline Yunnan & 17.41 & 15 & 15 \\
\hline Shaanxi & 20.25 & 16 & 16 \\
\hline Gansu & 20.26 & 15 & 15 \\
\hline Qinghai & 17.04 & 10 & 10 \\
\hline Ningxia & 20.09 & 15 & 15 \\
\hline Xinjiang & 08.91 & 10 & 10 \\
\hline
\end{tabular}




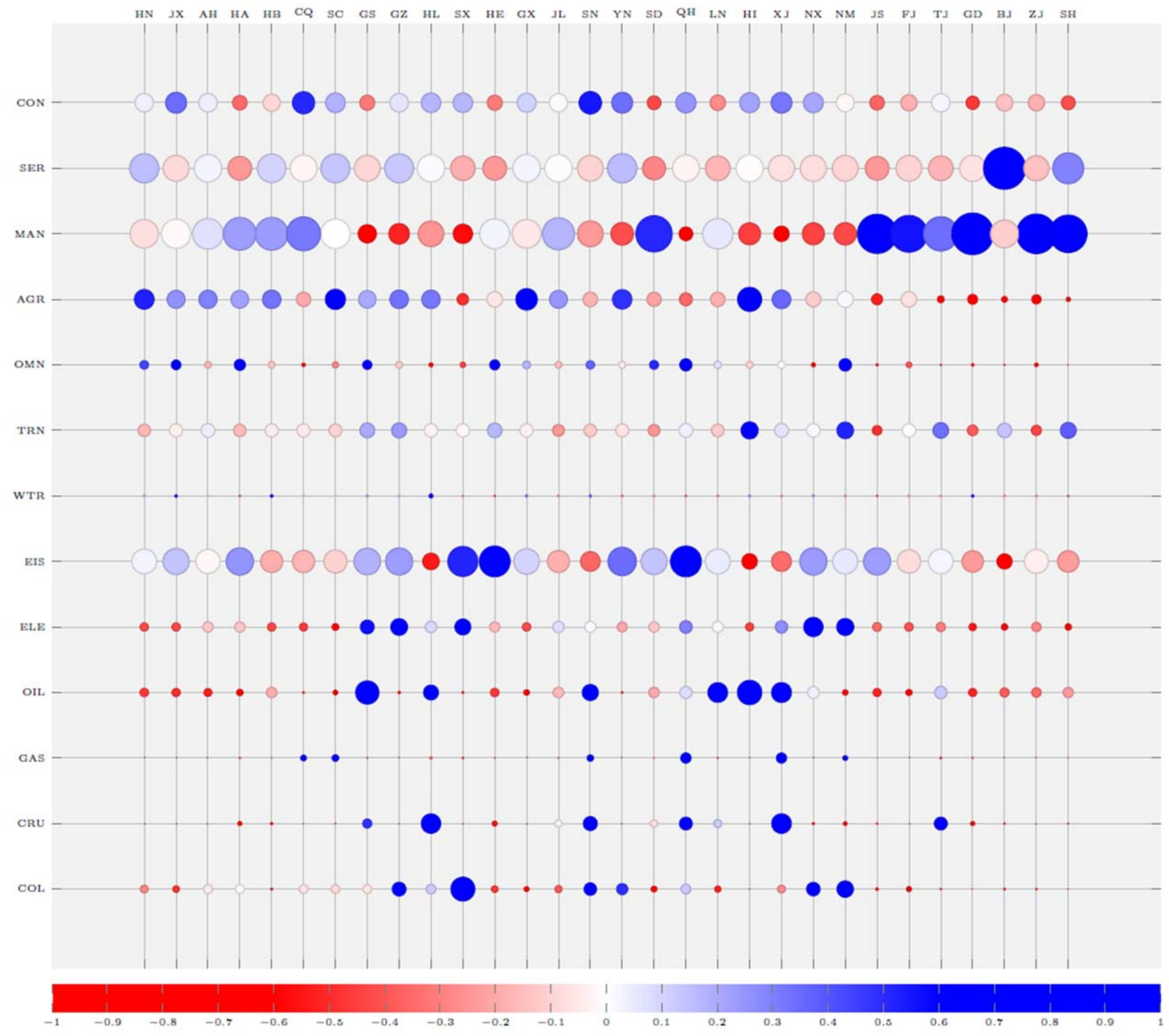

Figure A1. Industrial structure of each province in 2007. Bubble size indicates the percentage of the sector output. 


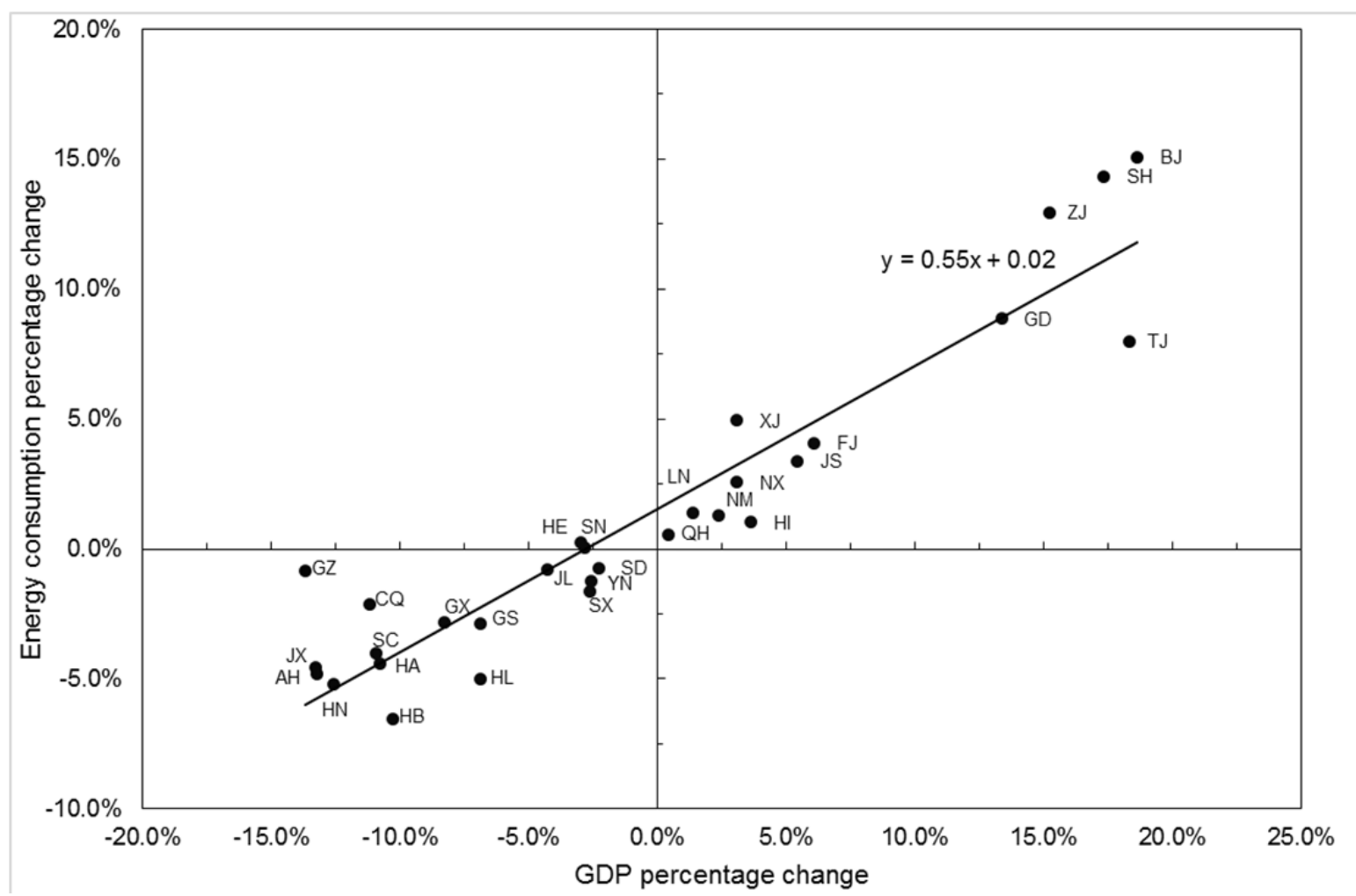

Figure A2. GDP percentage change vs. energy use percentage change with migration in 2020.

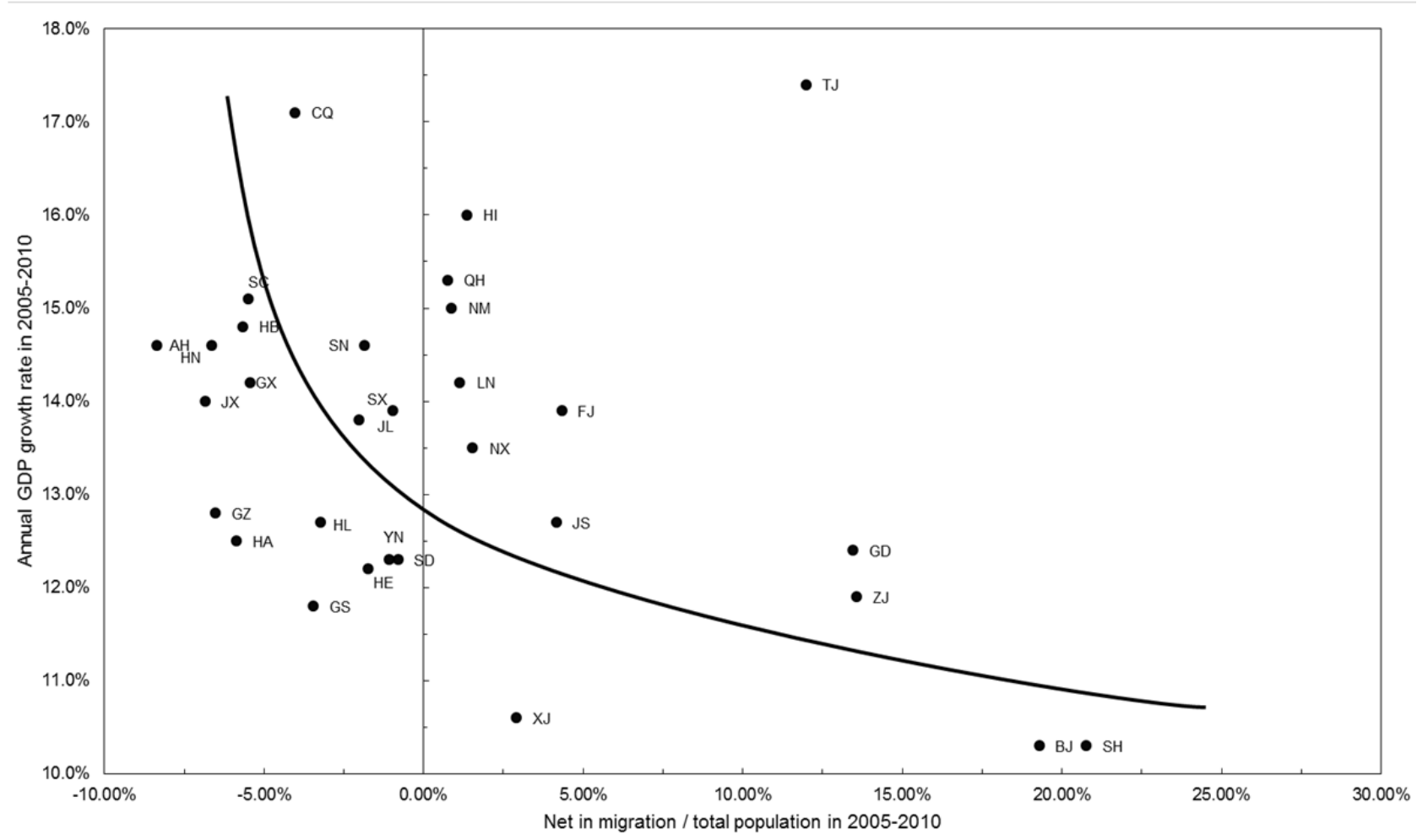

Figure A3. Net in-migration of provinces vs. annual GDP growth rate 